\title{
Customer lifetime network value: customer valuation in the context of network effects
}

\author{
Miriam Däs ${ }^{1} \cdot$ Julia Klier ${ }^{1} \cdot$ Mathias Klier $^{2} \cdot$ Georg Lindner $^{1} \cdot$ Lea Thiel $^{1}$
}

Received: 1 June 2016 / Accepted: 17 March 2017

(C) Institute of Applied Informatics at University of Leipzig 2017

\begin{abstract}
Nowadays customers are increasingly connected and extensively interact with each other using technologyenabled media like online social networks. Hence, customers are frequently exposed to social influence when making purchase decisions. However, established approaches for customer valuation mostly neglect network effects based on social influence. This leads to a misallocation of resources. Following a design-oriented approach, this paper develops a model for customer valuation referred to as the customer lifetime network value (CLNV) incorporating an integrated network perspective. By considering the customers' net contribution to the network, the CLNV reallocates values between customers based on social influence. Inspired by common prestige- and eigenvector-related centrality measures it incorporates social influence among all degrees of separation acknowledging its viral spread. Using a real-world dataset, we demonstrate the practicable applicability of the CLNV to determine individual customers' value.
\end{abstract}

Keywords Customer valuation - Customer lifetime value · Social influence $\cdot$ Network effects

\section{JEL classification M10}

Responsible Editor: Rainer Alt

Mathias Klier

mathias.klier@uni-ulm.de; https://www.uni-ulm.de/en/mawi/itop/ profil/staff/mathias-klier/

1 University of Regensburg, Universitätsstraße 31, D-93053 Regensburg, Germany

2 University of Ulm, Helmholtzstraße 22, D-89081 Ulm, Germany

\section{Introduction}

"We went from a connected world to a hyperconnected world" (Friedman 2013). Today, with around half of the world's population online, people are ever more closely connected and therefore interact to a great extend with each other using technology-enabled media (ITU 2016). In fact, the number of users of online social networks (OSNs) worldwide is expected to rise from over 2 billion in 2016 to almost 3 billion in 2020 (eMarketer 2014, 2016). The large number of digitally connected people exerts a great impact on all areas of life and companies can no longer ignore this revolutionary transformation of business and society with regard to future business success (e.g., Bond et al. 2012). Marketers therefore see social marketing and digital commerce as the top areas of future technology investment (Gartner Group 2015). By the rising number of connected customers, extensive social influence, for example through word-of-mouth (WOM), is exerted and dispersed with previously unknown reach, intensity, and speed. Consumer surveys reveal that up to $88 \%$ of online customers see WOM as the most trustable form of product recommendation (Nielsen 2015) and many customers rely on WOM when searching for information about products or services (Moon et al. 2010) or making purchase decisions (Chen and Xie 2008). In fact, especially in the younger generation around $85 \%$ of consumers naturally use OSNs for product research to gather information for their purchase decisions (Butler 2017; Solomon 2015). Furthermore, consumers more and more recommend products and companies via OSNs and also rely heavily on the recommendations of other consumers when it comes to purchase decisions (Chen and Xie 2008; Lis and Neßler 2014; Solomon 2015). This remarkable importance of customer-to-customer interactions has been on the one hand intensively discussed in prior research (Algesheimer and von Wangenheim 2006; Libai et al. 
2013; McAlexander et al. 2002; Rossmann et al. 2016). On the other hand, marketers state that WOM in social media is of particular relevance for their marketing activities and that they expect a strong growth of around $70 \%$ of marketing expenditures in this area in nearer future (WOMMA 2014). With respect to customer valuation, it is consequently crucial for companies to evaluate customers not isolated from each other but in a network context. For instance, think of customers who do not purchase anything but whose social influence induces purchases of several other customers. When neglecting network effects, such customers would be valued as unprofitable and would be ignored in a company's strategic decisions, although these customers do in fact add value to the company. An increase of the OSN share in the marketing budget up to $20 \%$ reveals the recognized importance of social media by marketers (The CMO Survey 2016).

Even though research has dealt extensively with customer valuation (Berger and Nasr 1998; Dwyer 1997), network effects in customer valuation have not been sufficiently investigated yet. Only very few studies started to address selected aspects of network effects in general customer valuation models (Domingos and Richardson 2001; Hogan et al. 2003). Also, regarding one of the most well-known customer valuation models, the customer lifetime value (CLV), research has considered social influence only rarely. Most of the existing approaches consider only direct network effects (i.e. influence among the first degree of separation) hence ignoring the viral spread of social influence inside a network beyond the first degree of separation (Klier et al. 2014) and/or concentrate on including network effects incentivized through referral campaigns (Kumar et al. 2007, 2010a, b; Lee et al. 2006) or other marketing and seeding programs (Hogan et al. 2004; Kumar et al. 2013; Libai et al. 2013) by compensating recommendations with a higher customer value. Further studies extend the CLV by increasing a customer's value based on network aspects arising outside of incentivized programs (Kumar et al. 2010a; Weinberg and Berger 2011). However, to the best of our knowledge, so far none of these studies has considered direct and indirect network effects in conjunction with the mirror-inverted effect yet: besides customers creating value in a network due to their direct and indirect influence on others, customers may also "owe" value to the network due to the social influence of other customers on their cash flows. Models neglecting this mirror-inverted effect are subject to double counting, as the additional value component representing network effects is once considered for the customer inducing other customers' cash flows and once for the customers actually generating these cash flows. In consequence, both double counting and the negligence of indirect network effects in existing customer valuation models lead to a misvaluation of individual customers and the whole customer base (i.e. a firm's customer equity (CE)), resulting, for example, in suboptimal (marketing) decisions and strategies.
Therefore, following a design-oriented approach (Hevner et al. 2004), the aim of this paper is to develop a novel model for customer valuation incorporating an integrated network perspective referred to as the customer lifetime network value (CLNV). We determine the value of a customer based on the present value of the individual cash flows generated by him/ her and the present value of his/her net contribution to the network. The CLNV is inspired by prestige- and eigenvector-related centrality measures like Katz prestige (Katz 1953) or the PageRank algorithm (Brin and Page 1998), thereby acknowledging the viral characteristic of networks. We demonstrate the applicability of the CLNV using a real-world case of a European OSN focusing on sports. Overall, the CLNV contributes to research and practice in three ways: First, it enables a well-founded valuation of individual customers incorporating an integrated network perspective; second, it allows an allocation of not only direct but also indirect network effects inside a network; and third, it facilitates a sound determination of a company's CE as the sum of all customers' CLNVs.

The paper is organized as follows: In the next section, we briefly review the theoretical foundations and related literature. We then develop the CLNV model as a new customer valuation method. Afterwards, the applicability of the CLNV is demonstrated by using a real-world case of a European OSN focusing on sports. Finally, we give a brief summary and conclude with a discussion on limitations and directions for further research.

\section{Literature background}

\section{Online customer networks and social influence}

Due to technology-enabled media, people are increasingly connected and extensively interact with each other. Against this background, companies face the challenge that customers can no longer be regarded as isolated individuals. Rather, customers are parts of (online) social networks enabling them to interact across personal and regional boundaries. Similar to social networks in general (Adamic and Adar 2003; Bampo et al. 2008; Kane et al. 2014; Wasserman and Faust 1994) online customer networks can formally be represented by a graph consisting of a set of nodes (representing the customers) and a set of edges (representing relations or interactions between pairs of customers).

Various studies have found the behavior of members in offline and online networks to be affected by social influence from other members in the network (Probst et al. 2013). Hereby, social influence can be induced through different forms of interactions, such as one-to-one or one-to-many WOM, observation and/or imitation, and information sharing with advice-seeking individuals (Arndt 1967; Herr et al. 1991; 
Iyengar et al. 2011b; Kumar et al. 2010a; Libai et al. 2013; Nitzan and Libai 2011; Wangenheim and Bayón 2007). Five causes of social influence in networks are discussed in literature (Hinz et al. 2014; Iyengar et al. 2011b; Kane et al. 2014; Van den Bulte and Wuyts 2007): First, information transferred in interactions may increase the awareness of and interest for a topic such as a product (Katz and Lazarsfeld 1955). Second, information about costs and benefits of actions reduces search efforts and uncertainty and therefore increases adaption (Iyengar et al. 2011a). Third, normative pressure to fulfill the expectations of others (Asch 1951), or fourth, imminence of real status and competitive disadvantages can induce a change in behavior. Fifth, network externalities can increase the consumption of goods, i.e., with every additional customer consuming a good the value of consuming this particular good increases (Granovetter 1978; Katz and Shapiro 1994).

Many authors focus on direct social influence, i.e., influence between two users that directly interact with each other (e.g., Klier et al. 2014). However, social influence in OSNs does not stop at the first degree of separation as it takes place with an extended scope, speed, complexity, and independent of time and place (Gruzd and Wellman 2014). To the contrary, content can spread "virally" through the entire network (Hogan et al. 2004; Nahon and Hemsley 2013). Thus, it affects not solely the users directly, but also indirectly connected to the source. Such indirect influence, sometimes called the "ripple effect" (Hogan et al. 2004; Oestreicher-Singer et al. 2013), has been subject of research in context of offline social networks (Granovetter 1973; Harary et al. 1965) as well as OSNs (Goldenberg et al. 2009; Gruzd and Wellman 2014; Hinz et al. 2011; Hogan et al. 2004; Kiss and Bichler 2008). However, despite the viral diffusion of information in networks as a whole, research on indirect effects is often limited to influence at the first degree of separation (Gruzd and Wellman 2014). Recent studies, for instance Gruzd and Wellman (2014), therefore demand and predict a shift from social one-to-one influence to a more network-centric view, called "networked influence" (Gruzd and Wellman 2014, p. 1255).

Prior research shows that social influence, both direct and indirect, is of high practical relevance for companies: On the one hand, connections between customers can be used for referrals. Hence, social influence can help companies to acquire new customers at relatively low acquisition costs (Kumar et al. 2007, 2010a, b; Lee et al. 2006). Villanueva et al. (2008) and Schmitt et al. (2011) even found that in the long term customers acquired through customer referrals are more profitable for a company than customers acquired through traditional marketing. On the other hand, social influence between customers can affect the "belief, attitude, or behavior" of existing customers (Erchul and Raven 1997, p. 138), including their purchase decisions and loyalty (Algesheimer and von Wangenheim 2006; Hogan et al.
2004; Kumar et al. 2010a; Nitzan and Libai 2011; Soares and Pinho 2014; Weinberg and Berger 2011). Consequently, companies increasingly try to actively manage customers' interactions by identifying and targeting those customers with large influence on other customers, so-called influencers (Bampo et al. 2008; Goldenberg et al. 2009; Gruzd and Wellman 2014; Heidemann et al. 2010; Hinz et al. 2011; Trusov et al. 2010; Zhang et al. 2011). Recent research has highlighted that, in addition to customer characteristics such as age, gender, education, and expertise (Aral and Walker 2012; de Valck et al. 2009; Eccleston and Griseri 2008; Gladwell 2000; Katona et al. 2011; Watts and Dodds 2007; Zhang et al. 2011), the structure of the network can affect a customer's influence on other customers. In this context, a customer's connectivity, for example his/her number of direct or indirect connections, is shown to affect a customer's influential power (Algesheimer and von Wangenheim 2006; Ganley and Lampe 2009; Goldenberg et al. 2009; Hinz et al. 2011; Kiss and Bichler 2008; Nitzan and Libai 2011). Additionally, as inactive connections do not imply social influence, customers' communication activities or interactions are increasingly used to identify influencers (Cheung and Lee 2010; de Valck et al. 2009; Heidemann et al. 2010; Kane et al. 2014; Mtibaa et al. 2010). To take into account the entire network structure when identifying influencers, several authors have started to implement approaches based on prestige- and eigenvector-related centrality measures like Katz prestige (Katz 1953), Bonacich centrality (Bonacich 1972), or the PageRank algorithm (Brin and Page 1998) (cf. e.g., Heidemann et al. 2010; Kiss and Bichler 2008; Mtibaa et al. 2010). Their approaches use iterative calculations to quantify a user's influence in a network based on the users' connections in the network.

In this paper, we argue that it is essential to not only identify and target influencers but to likewise consider their social influence in customer valuation. Thus, a customer's value should not solely consider the cash flows generated by $\mathrm{him} / \mathrm{her}$ (e.g., through purchases) but also the network effects in terms of his/her direct and indirect social influence on the cash flows of others in the network (e.g., through WOM) and vice versa.

\section{Customer valuation and network effects}

Customer valuation has been subject of extensive prior research (Berger and Nasr 1998; Kotler and Armstrong 1996). The classic CLV constitutes one of the most well-known customer valuation models. It is defined as the sum of a customer's discounted present and expected future cash flows (Berger and Nasr 1998). Hence, it considers the profit a company is expecting to earn with a customer over his/her lifetime therefore reflecting all monetary and non-monetary aspects like customer satisfaction which some day find expression in 
the customer's cash flows (Gupta et al. 2006). The CLV and its various adaptions have proven useful in a variety of contexts such as segmenting customers, optimizing the timing of product offerings, evaluating competitor companies, or supporting merger and acquisition decisions (Kumar et al. 2004, 2008; Venkatesan and Kumar 2004).

However, recent studies (Verhoef and Lemon 2013) show that it is essential to consider network effects in customer valuation. Indeed, a customer's value can no longer be based solely on a customer's purchase behavior. Rather, a customer's contribution to a company goes beyond direct transactions and includes elements like the value of social influence (Domingos and Richardson 2001; Hogan et al. 2003; Klier et al. 2014; Kumar et al. 2010a; Malthouse et al. 2013; Weinberg and Berger 2011). Against this background, few authors started to address selected aspects of network effects in general customer valuation models (Domingos and Richardson 2001; Hogan et al. 2003). Hogan et al. (2003), for instance, incorporate direct and indirect network effects when assessing the value of a lost customer using a product growth model. They argue that a company losing a customer does not only lose his/her future cash flows but also the cash flows of other customers due to slower customer acquisition resulting from reduced social influence. Another example is the work of Domingos and Richardson (2001) who model a Markov random field distinguishing two components: the customer's intrinsic value representing the value s/he generates individually via purchases, and the customer's network value representing the value $\mathrm{s} / \mathrm{h}$ generates via social influence on other customers.

Also with respect to the CLV, prior research has considered selected aspects of network effects (Hogan et al. 2004; Kumar et al. 2007, 2013, 2010a, b; Lee et al. 2006; Libai et al. 2013; Weinberg and Berger 2011). Thereby, most of the studies focus on network aspects arising in campaign contexts, i.e., incentivized through marketing campaigns or seeding programs (Hogan et al. 2004; Kumar et al. 2007; Kumar et al. 2013; Kumar et al. 2010b; Lee et al. 2006; Libai et al. 2013). Lee et al. (2006) and Kumar et al. (2007), for instance, take account of social influence in form of referral campaigns (Kumar et al. 2007; Kumar et al. 2010b). When valuating a customer, these studies consider the original cash flows generated by a customer (as in the classic CLV) and add a second component, often called "customer referral value" (CRV), covering cash flows of other customers that have been induced by him/her through a referral. Lee et al. (2006) consider a customer's original cash flows as well as the savings in acquisition costs for new customers obtained through that customer's social influence. Kumar et al. (2007) estimate a customer's referral value by determining either the entire transaction value (i.e., the net present value of all future cash flows and the savings in acquisition cost) or solely the savings in acquisition cost for customers who would not have joined the company without his/her referral (Kumar et al. 2007, 2010b). Both Lee et al. (2006) and Kumar et al. (2007) focus on direct network effects considering only referrals among the first degree of separation (like Klier et al. (2014)). In addition, Hogan et al. (2004), Libai et al. (2013), and Kumar et al. (2013) measure the value of WOM incentivized through advertising or seeding programs. While Libai et al. (2013) establish the value of entire WOM-seeding programs using agentbased modeling, Hogan et al. (2004) determine the value of individual customers in context of WOM by adding all cash flows of other customers in the network induced by their WOM to these customers' CLV. Both studies acknowledge the fact that WOM spreads deep inside a network (i.e. beyond the first degree of separation). The approach of Libai et al. (2013), however, does not allow for a definite determination of indirect network effects. Kumar et al. (2013) measure the monetary impact of (incentivized) WOM by, first, identifying influencers based on historical data, second, encouraging those influencers with incentives to share their opinion, and third, determining the value of influence for each customer. Hereby, a customer's value of influence is composed by the CLV of all people that are influenced by him/her ("influencees") and, incorporating indirect network effects, a share of the cash flows those influencees received for influencing others.

Next to that, further studies have implemented CLV-based approaches measuring social influence in non-campaign contexts, i.e., arising outside of incentivized marketing campaigns or seeding programs (Kumar et al. 2010a; Weinberg and Berger 2011). For example, Kumar et al. (2010a) introduce the "customer influencer value" as a value component comprising all network effects that are not formally incentivized by a company. For instance, effects occurring due to regular user interaction in social media are included. They quantify the customer influencer value based on a customer's number of connections, the strength of those connections, and the "emotional valence" of the customer's interactions (Kumar et al. 2010a, p. 302). They do, however, not focus on social influence "beyond the close social network" of a customer (Kumar et al. 2010a, p. 301). Similarly, Weinberg and Berger (2011) define the total value of a customer, referred to as the "connected customer lifetime value", as the sum of the CLV, the customer referral value, and the "customer social media value". The latter is determined by multiplying the CLV with impact factors considering the influential power and the customer's respective engagement level for each social medium used. They thereby include solely direct social media based nonincentivized effects (Weinberg and Berger 2011).

Summing up, previous studies have started to consider selected aspects of network effects in customer valuation. They emphasize that besides the cash flows 
generated by a customer when purchasing products or services, a customer's value should also consider the effect of his/her social influence on the cash flows of other customers in the network. To do so, previous work suggests adding further value components to the classic CLV representing the value of positive network effects.

\section{Research gap}

Prior studies have started to include the relevance of customers with high social influence on other customers in customer valuation. However, they have not considered the mirror-inverted effect yet: besides customers creating value in the network due to their influence on others, customers may also "owe" value to the network due to the social influence of others on their purchasing behaviors. Hence, existing models are subject to double counting, as the additional value component representing the network effects is considered multiple times - once for the customers inducing other customers' cash flows and once for the customers actually generating these cash flows. Overestimating the value of a customer (e.g., due to double counting when calculating his/her CLV) might lead to wrong decisions. For example, potential new customers might be acquired or existing customers might be bound at too high cost (exceeding their "true" value for the firm). Indeed, double counting is a serious issue if it is important to have a best possible indication regarding the "true" value of a customer for the firm. Several studies have acknowledged that their approaches cause double counting (Kumar et al. 2010b; Weinberg and Berger 2011). Kumar et al. (2010a, p. 308), for example, recognize that "[a]lthough CLV and CRV involve separate metrics, they cannot be added up across all customers". If a company's CE is calculated based on these models, it is admitted "[...] that the sum of all customers' CCLV [connected customer lifetime value] is greater than the sum of all customers' CLV" (Weinberg and Berger 2011 , p. 342). Next to that, with regard to the diffusion of social influence in networks, only a few studies have started to acknowledge indirect network effects when valuating customers. Consequently, most of the existing valuation models underestimate the true value of customers' influence beyond the first degree of separation (Klier et al. 2014; Kumar et al. 2007) and at the same time overestimate the value of customers being the intermediaries of those. Besides, even fewer studies provide an actual method to allow the computation of indirect network effects. In fact, we found only two CLV-based approaches (Hogan et al. 2004; Kumar et al. 2013) enabling an allocation of both direct and indirect network effects in customer valuation.

\section{Modeling the customer lifetime network value}

\section{Basic setting}

We consider a network of interlinked customers. The network can be represented by a set of nodes and a set of directed and weighted edges. Each node represents a customer and each edge represents the direction and strength of influence between a pair of customers, for example induced by WOM spread through private messages (Adamic and Adar 2003; Bampo et al. 2008; Heidemann et al. 2010; Hinz et al. 2011) or other sorts of user interaction. Customers in the network can generate cash flows through purchases. The existence and amount of these cash flows, however, may depend on the influence of other customers in the network. Note that the influence between two customers can be direct as well as indirect. Indirect influence exists when customers, who have been influenced by another customer, again influence others.

To illustrate the setting, we use an example of a network of four customers (1, 2, 3, and 4) who generate cash flows and positively influence each other both directly and indirectly (cf. Fig. 1). The size of a node represents the amount of cash flows generated by a customer. Direct influence between a pair of customers is visualized by an edge between two customers. The direction of the edge represents the direction of influence; the size of the edge characterizes the strength of influence. Indirect influence between two customers is represented by two or more edges forming a path (e.g., from customer 3 to customer 4 via customer 2).

First, we consider direct network effects. Both customers 2 and 3 exert direct influence on customer 1 . Thus, parts of the cash flows generated by customer 1 might depend on the influence of customers 2 and 3, i.e., they might not have been generated without their positive influence. Consequently, the value of customer 1 would be overestimated when solely looking at the cash flows generated individually by him/her. At the same time, a customer's value can be underestimated when regarding his/her cash flows as isolated (Domingos and Richardson 2001; Hogan et al. 2003; Weinberg and Berger 2011). Customer 3, for example, might highly influence customers 1 and 2. Hence, the value of customer 3 within this network might be higher than indicated by his/her individually generated cash flows. Second, we can observe not only direct but also indirect influence in the customer network. Customer

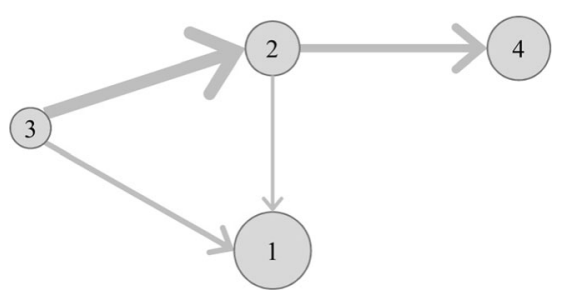

Fig. 1 Illustration of a customer network 
3 directly influences customer 2, who again exerts direct influence on customer 4 . Thus, along this path, customer 3 might indirectly influence customer 4. Parts of customer 4's cash flows may therefore not only depend on the influence of customer 2, but also on the influence of customer 3. Hence, considering solely direct influence would lead to an overestimation of the value of customer 2 and an underestimation of the value of customer 3 . This rather straight forward example already shows that enhancing classic valuation methods (Berger and Nasr 1998) by accounting for not only direct (Klier et al. 2014) but also indirect influence of customers is crucial for companies, as ignoring such network effects when deciding "which customer to market to can lead to severely suboptimal decisions" (Domingos and Richardson 2001, p. 57).

\section{Basic idea}

The aim of this paper is to develop an approach for valuating customers in the presence of direct and indirect network effects induced by the influence among customers. As a starting point, we assume the structure of the customer network (i.e., the number of nodes and the directed and weighted edges) and each customer's cash flows as given. To calculate the CLNV, we divide the customer value into two components: (1) the individual cash flows generated by him/her individually and (2) a network component incorporating direct and indirect network effects, which represents his/her net contribution to the network, referred to as $\Delta$ network contribution:

\section{$C L N V=$ present value of individual cash flows \\ + present value of $\Delta$ network contribution}

Compared to previous studies that have started to include network effects in customer valuation (Kumar et al. 2007, 2010a, b; Libai et al. 2013; Weinberg and Berger 2011), our network component, $\Delta$ network contribution, differs out of two reasons: First, while previous work simply includes the effect a customer has on the network, our approach proposes to consider the mirror-inverted effect as well, i.e., the effect the network has on the customer. Thus, we are not solely increasing a customer's value when $\mathrm{s} / \mathrm{he}$ is exerting influence on others, our approach also decreases a customer's value when his/her cash flows are induced by the influence of others. In contrast to existing research on network effects in customer valuation, our network component can consequently be positive, negative, and zero, depending on the influence or susceptibility of the respective customer. Second and instead of a mere incorporation of direct network effects (Klier et al. 2014), we propose to incorporate also indirect influence in our network component. Thereby, our approach is inspired by the basic idea of prestige- and eigenvector-related centrality measures like Katz prestige (Katz 1953), Bonacich centrality (Bonacich 1972), or the PageRank algorithm introduced by Brin and Page (1998). In contrast to other centrality measures, like degree centrality (cf. Freeman 1979), these measures are able to consider direct and indirect influence in networks. Indeed, PageRank is probably the most well-known algorithm to rank a web page's importance in the World Wide Web (WWW) based on the links pointing to this web page. In particular, the greater the amount of links a web page receives and the higher their importance, the greater is the importance of a web page itself (Brin and Page 1998; Page et al. 1999). By "iterating the computation until it converges" (Page et al. 1999, p. 4), the algorithm allows for a full network approach considering the entire network structure. Since our approach aims at accomplishing the latter for customer valuation such an iterative approach considering the customers' influence among all degrees of separation seems particularly promising to determine $\Delta$ network contribution. Note that, while our work is inspired by the iterative idea of prestige- and eigenvector-related centrality measures, it is not possible to directly use or simply adapt these measures for our purpose. With respect to the PageRank algorithm, for example, there is a significant difference to our context since we do not increase a node's value based on the edges pointing to it but based on the edges pointing away from it. This is due to the fact that in our case a customer's value is higher the more customer s/he influences (i.e., edges pointing from him/her to other customers). Considering the mirror-inverted effect, a node's value is decreased based on the edges pointing to it.

\section{Basic model of the customer lifetime network value}

Along the lines of the classic CLV (Berger and Nasr 1998), we define the CLNV as the present value (discount rate: $d \in \mathbb{R}^{+}$) of a customer's assigned current and expected future cash flows with respect to the expected lifetime $T \in \mathbb{N}$ of the customer relationship. ${ }^{1}$ Thereby, building on previous works (Domingos and Richardson 2001; Weinberg and Berger 2011), we define the customer's assigned cash flows as the sum of the expected cash flows $C F_{i, t} \in \mathbb{R}$ generated by customer $i$ in period $t$ and a network component. Latter differs from existing research: First, instead of solely including the positive effect a customer has on the network (e.g., induced by referrals to others), we also consider the positive effect the network has on the customer (e.g., induced by referrals of others). Second, we take the entire network structure into account, thus incorporating also indirect influence among customers. Hence, the network component is determined by subtracting the cash flows $C F_{i, t}^{\text {influenced }} \in \mathbb{R}$ of customer $i$ that are induced by direct and indirect positive influence of other customers from the

\footnotetext{
${ }^{1}$ An overview of the mathematical notation is provided in Table 6 (cf. Appendix 1).
} 
cash flows $C F_{i, t}^{\text {influence }} \in \mathbb{R}$ of other customers that are induced by the direct and indirect positive influence of customer $i$. The CLNV of a customer $i$ is defined as follows:

$\mathrm{CLNV}_{i}=\sum_{t=0}^{T} \frac{C F_{i, t}+\left(C F_{i, t}^{\text {influence }}-C F_{i, t}^{\text {influenced }}\right)}{(1+d)^{t}}$

$C F_{i, t}^{\text {influence }}$ comprises all cash flows of other customers $j$ in period $t$ that have been induced directly or indirectly by customer $i$. The respective set of customers $j$ being influenced directly by customer $i$ in period $t$ is referred to as Influenced $(i, t)$. Along the same lines, we define Influence(j, $t$ ) as the set of customers exerting direct influence on customer $j$ in period $t$. Referring to a customer $j \in \operatorname{Influenced}(i, t)$, $C F_{i, t}^{\text {influence }}$ on the one hand comprises cash flows induced by the influence of customer $i$ which are generated by customer $j$ and are thus part of $C F_{j, t}$. On the other hand, $C F_{i, t}^{\text {influence }}$ must also take into account the indirect influence of customer $i$ via customer $j$ on other customers in the network. Therefore, we build our approach on the basic idea of prestige- and eigenvector-related centrality measures and add an iterative component $C F_{j, t}^{\text {influence }}$. By this means, a customer $i$ 's influence among all degrees of separation is included in $C F_{i, t}^{\text {influence }}$. The share of a customer $j$ 's cash flows $C F_{j, t}$ and $C F_{j, t}^{\text {influence }}$, which traces back to the influence of other customers in the network, is represented by the parameter $\alpha \in\left[0,1\left[.^{2}\right.\right.$ The respective cash flows $\left(\alpha \cdot C F_{j, t}\right.$ and $\left.\alpha \cdot C F_{j, t}^{\text {influence }}\right)$ are allocated to the customers exerting influence on customer $j$ in period $t$. Thereby, to ensure a fair distribution of induced cash flows among all influencers, customer $i$ is ascribed the share $\frac{s_{t}^{i \rightarrow j}}{\sum_{k \in \text { Influence }(j, t)} s_{t}^{k \rightarrow j}}$ depending on his/her relative strength of in- fluence $s_{t}^{i \rightarrow j} \in \mathfrak{R}$ on customer $j$ in period $t$ with respect to the strength of influence $s_{t}^{k \rightarrow j}$ of all customers $k \in \operatorname{Influence}(j, t)$ on customer $j$. For each degree of separation the influence and therefore the share of the cash flows tracing back to the influence of customer $i$ is reduced by the factor $\alpha \in[0 ; 1[$. Therefore, a diminishing effect in $\alpha$ with $0 \leq \alpha<1$ (i.e. $\alpha$, $\alpha^{2}, \alpha^{3}, \ldots$ where $1>\alpha>\alpha^{2}>\alpha^{3}>\ldots>0$ holds) can be observed. Due to this diminishing effect and in accordance with the convergence of the geometric series for parameters from the interval $[0 ; 1$ [ the single summands approach zero and $C F_{i, t}^{\text {influence }}$ converges. Altogether $C F_{i, t}^{\text {influence }}$ can be expressed as denoted in Eq. (2).

$$
C F_{i, t}^{\text {in fluence }}=\sum_{j \in \operatorname{In} \text { fluenced }(\mathrm{i}, \mathrm{t})} \frac{s_{t}^{i \rightarrow j}}{\sum_{k \in \operatorname{In} \text { fluence }(\mathrm{j}, \mathrm{t})} s_{t}^{k \rightarrow j}}\left(\alpha \cdot C F_{j, t}+\alpha \cdot C F_{j, t}^{\text {in fluence }}\right)
$$

Along the same lines, we define $C F_{i, t}^{\text {influenced }}$ as the sum of all cash flows of customer $i$ in period $t$ that are induced by the direct and indirect influence of other customers. Thereby, both the cash flows generated by customer $i\left(C F_{i, t}\right)$ and the cash flows induced by the direct or indirect influence of customer $i\left(C F_{i, t}^{\text {influence }}\right)$ have to be considered accordingly. Thus, $C F_{i, t}^{\text {influenced }}$ is defined as stated in Eq. (3) (with $\sum_{j \in \operatorname{Influence}(i, t)} \frac{s_{t}^{j \rightarrow i}}{\sum_{k \in \operatorname{lnfluence}(i, t)} s_{t}^{k \rightarrow i}}=1$ ):

$$
\begin{aligned}
C F_{i, t}^{\text {influenced }} & =\sum_{j \in \text { Influence }(\mathrm{i}, \mathrm{t})} \frac{s_{t}^{j \rightarrow i}}{\left.\sum_{k \in \operatorname{Influence}(\mathrm{i}, \mathrm{t})}\right)_{t}^{k \rightarrow i}}\left(\alpha \cdot C F_{i, t}+\alpha \cdot C F_{i, t}^{\text {influence }}\right) \\
& =\alpha \cdot C F_{i, t}+\alpha \cdot C F_{i, t}^{\text {influence }}
\end{aligned}
$$

Finally, based on Eqs. (1) to (3) we define the CLNV of a customer $i$ as follows:

$\operatorname{CLNV}_{i}=\sum_{t=0}^{T} \frac{C F_{i, t}+\sum_{j \in \operatorname{Influenced}(i, t)} \frac{s_{t}^{i \rightarrow j}}{\sum_{k \in \operatorname{Influence}(j, t)} s_{t}^{k \rightarrow j}}\left(\alpha \cdot C F_{j, t}+\alpha \cdot C F_{j, t}^{\text {influence }}\right)-\left(\alpha \cdot C F_{i, t}+\alpha \cdot C F_{i, t}^{\text {influence }}\right)}{(1+d)^{t}}$

\footnotetext{
${ }^{2}$ It is generally possible to define the share of cash flows tracing back to influence in the network as a customer and/or period specific parameter. To do so, the parameter $\alpha$ may for example be replaced by the parameter $\alpha_{t}^{j} \in[0$, 1 [ representing the share of customer $j$ 's cash flows in period $t$, which traces back to the influence of other customers in the network. By means of the parameter $\alpha_{t}^{j}$ it can be considered that some customers in the network may be more susceptible to social influence than others and that this fact may vary over time. For reasons of simplicity, we refrain from this differentiation at this point.
}

\section{Extension of the basic model considering negative social influence}

In the basic model of the CLNV as introduced above we focused on positive social influence and did not include the effect of possible negative WOM (Kumar et al. 2010a; Weinberg and Berger 2011). Nevertheless, it is important to keep in mind that negative influence among customers may indeed result in cash flow 
potential of customers that cannot be realized ("economic damage"). To address this issue, in this subsection, based on Eq. (1) of the basic model of the
CLNV, we propose an extension subtracting an additional value component to account for the effect of possible negative social influence:

$\mathrm{CLNV}_{i}=\sum_{t=0}^{T} \frac{C F_{i, t}+\left(C F_{i, t}^{\text {influence}}-C F_{i, t}^{\text {influenced }}\right)-\left(C F_{i, t}^{\text {negative_influence }}-C F_{i, t}^{\text {negatively_influenced }}\right)}{(1+d)^{t}}$

$C F_{i, t}^{\text {negative_influence }}$ comprises the additional cash flow potential of other customers that cannot be realized in period $t$ due to direct or indirect negative influence of customer $i$. $C F_{i, t}^{\text {negatively_influenced }}$ denotes the additional cash flow potential of customer $i$ that cannot be realized in period $t$ due to negative influence of other customers on customer $i$. Analogously to the term $\left(C F_{i, t}^{\text {influence }}-C F_{i, t}^{\text {influenced }}\right)$ representing the network effects attributable to positive influence in the basic model of the CLNV, the network effects resulting from negative influence are considered in an additional network component $\left(C F_{i, t}^{\text {negative_influence }}-C F_{i, t}^{\text {negatively_influenced }}\right)$ which is subtracted in the extended model (cf. Eq. (5)). By this means, positive and negative influence are considered in a well-founded way not mixing up the respective effects. Thereby, $C F_{i, t}^{\text {negative_influence }}$ and $C F_{i, t}^{\text {negatively_influenced }}$ can be defined along the lines of the respective parameters of the basic model incorporating direct and indirect network effects (cf. Eqs. (2) and (3)), however, not referring to positive influence and cash flows induced by positive influence in period $t$ but to negative influence and additional cash flow potential of customers that cannot be realized in period $t$ due to negative influence.

\section{Illustrative example}

\section{Basic model of the customer lifetime network value}

Consider Fig. 2 for a sample customer network to illustrate the application of the CLNV. In this example we supplemented the network previously introduced by further information on cash flows, $C F_{i, t}$, and the strength of positive influence, $s_{t}^{i \rightarrow j}$. A time horizon of one period $(T=1)$, a discount rate of $10 \%$

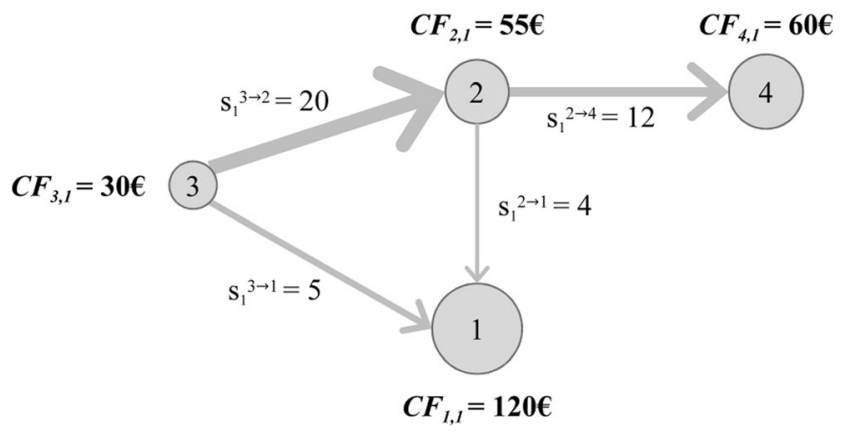

Fig. 2 Sample customer network $(d=0.10)$, and a share of cash flows tracing back to influence in the network of 50\% $(\alpha=0.50)$ are assumed.

First, $C F_{i, t}^{\text {influence }}$ is calculated using Eq. 2. In most realworld cases, manually calculating $C F_{i, t}^{\text {influence }}$ for all nodes might be difficult due to its iterative component (to see how to cope with this issue cf. subsection "Application of the Customer Lifetime Network Value"). However, in our example, with customers 1 and customer 4 not exerting any influence resulting in $C F_{1,1}^{\text {influence }}=C F_{4,1}^{\text {influence }}=0 €$, a manual calculation is possible and for illustration purposes advantageous. The cash flows induced by customer 2 can be calculated as follows: $C F_{2,1}^{\text {influence }}=4 / 9 \cdot(0.50 \cdot 120 €+0.50 \cdot 0 €)+12 /$ $12 \cdot(0.50 \cdot 60 €+0.50 \cdot 0 €)=56.67 €$. In this respect, $4 / 9$ represents the relative strength of influence customer 2 exerts on customer 1, calculated by comparing the absolute strength of influence of customer 2 on customer $1\left(s_{1}^{2 \rightarrow 1}=4\right)$ to the overall strength of influence that customer 1 receives from the network (i.e., $s_{1}^{2 \rightarrow 1}+s_{1}^{3 \rightarrow 1}=9$ ). The factor $12 / 12$ is calculated analogously. On this basis, $C F_{3,1}^{\text {influence }}$ can be determined to $C F_{3,1}^{\text {influence }}=5 / 9 \cdot(0.50 \cdot 120 €+0.50 \cdot 0 €)+20 / 20 \cdot(0.50 \cdot 55$ $€+0.50 \cdot 56.67 €)=89.17 €$. Second, $C F_{i, t}^{\text {influenced }}$ is calculated for each customer applying Eq. 3. For example, $C F_{3,1}^{\text {influenced }}$ yields $0 €$, as customer 3 is not influenced by any other customer. For customer 2, however, $C F_{2,1}^{\text {influenced }}$ is calculated as follows: $C F_{2,1}^{\text {influenced }}=20 / 20 \cdot(0.50 \cdot 55 €+0.50 \cdot 56.67 €)=55.84$ $€$. Finally, the CLNV can be calculated using Eq. 4. For customer 3, this results in $C L N V_{3}=(30 €+89.17 €-0 €) /(1+$ $0.10)^{1}=119.17 € / 1.10^{1}=108.34 €$. Table 1 summarizes the results. Customer 1 and customer 4 have a negative net contribution to the network $\left(C F_{i, 1}^{\text {influence }}-C F_{i, 1}^{\text {influenced }}\right)$, while customer 3 has a highly positive one and customer 2's is close to zero.

To illustrate the impact of network effects in customer valuation, we compare the CLNV of all customers with the classic CLV of $109.09 €$ for customer 1, 50.00 $€$ for customer 2, 27.27€ for customer 3 , and $54.54 €$ for customer 4 (cf. present value of individual cash flows in Table 1). While customer 3 is not influenced by other customers, customer 1 and customer 4 "owe" a share of their cash flows to the network. As a consequence, their 
Table 1 CLNV example (basic model)

\begin{tabular}{|c|c|c|c|c|}
\hline & Customer 1 & Customer 2 & Customer 3 & Customer 4 \\
\hline Individual cash flows $C F_{i, 1}[€]$ (present value $\left.[€] / C L V_{i}\right)$ & $120.00(109.09)$ & $55.00(50.00)$ & $30.00(27.27)$ & $60.00(54.54)$ \\
\hline$\Delta$ network contribution $[€]$ (present value $[€]$ ) & $-60.00(-54.55)$ & $0.83(0.75)$ & $89.17(81.07)$ & $-30.00(-27.27)$ \\
\hline$C F_{i, 1}^{\text {influence }}[€]$ (present value $[€]$ ) & $0.00(0.00)$ & $56.67(51.51)$ & $89.17(81.07)$ & $0.00(0.00)$ \\
\hline$C F_{i, 1}^{\text {influenced }}[€]$ (present value $[€]$ ) & $60.00(54.55)$ & $55.84(50,76)$ & $0.00(0.00)$ & $30.00(27.27)$ \\
\hline$C L N V_{i}[€]$ & 54.54 & 50.75 & 108.34 & 27.27 \\
\hline
\end{tabular}

CLNV is substantially lower than their classic CLV. In contrast, the CLNV for customer 3 is considerably higher than the classic CLV, since s/he is inducing a share of the cash flows of the customers 1, 2, and 4 . For customer 2, the CLNV and the classic CLV are almost identical, as the cash flows of other customers induced by the influence of customer 2 roughly equal the cash flows that customer 2 "owes" to the network due to the influence of customer 3 . This reflects the basic idea of our model reallocating cash flows without changing the overall value of the network. The sum over the $C L N V_{i}$ and the $C L V_{i}$ for all four customers both yield $240.90 €$.

To illustrate the impact of indirect network effects, we investigate the customers' values when neglecting the iterative component of Eq. 2. The value of customer 3, for instance, is underestimated by about $25 €(24 \%)$ when solely focusing on direct influence. Since customer 2 is the intermediary of customer 3's indirect influence on the network, the value of customer 2 is consequently overestimated by about $25 €(50 \%)$ when neglecting indirect influence. For the customers 1 and 4 no differences are observed. This is due to the fact that they neither are intermediaries nor exert indirect influence inside the network. Thus, this example illustrates the importance of incorporating not only direct but also indirect network effects in customer valuation.

\section{Extension of the basic model considering negative social influence}

Considering negative social influence can be illustrated in a similar manner. Indeed, the underlying idea of the model's extension is to reallocate additional cash flow potential of customers that cannot be realized due to negative influence considering direct and indirect network effects following the iterative idea already pursued to account for positive influence in the basic model (cf. Eqs. (2) and (3)). Thereby, considering the respective additional cash flow potential of customers that cannot be realized due to negative influence once for the customers negatively influenced (cf. $C F_{i, t}^{\text {influenced }}$ ) and once for the customers exerting negative influence (cf. $C F_{i, t}^{\text {influence }}$ ) with different signs (cf. Eq. (5)) ensures that the overall value of the network does not change compared to the basic model ("zero-sum logic" of the model extension).

To illustrate the basic idea of the extension of the basic model, we slightly supplement the example introduced before (cf. Fig. 2) as follows: Customer 4 exerts direct negative influence on customer 1 . The additional cash flow potential of customer 1 that cannot be realized due to this negative influence is $20 €$ (i.e. $C F_{1,1}^{\text {negatively_influenced }}=20 €$ ). As we do not observe negative influence between any other pair of customers, it follows that $\left(C F_{1,1}^{\text {negative_influence_}}-C F_{1,1}^{\text {negatively_influenced }}\right)=(0 €-20 €)=-20$ $€$ for customer $1,\left(C F_{4,1}^{\text {negative_influence }}-C F_{4,1}^{\text {negatively_influenced }}\right)=$ $(20 €-0 €)=20 €$ for customer 4 , and accordingly $0 €$ for all other customers $i$ with $i \in\{2,3\}$. Incorporating the additional value component to account for the effect of negative influence in the CLNV using Eq. (5) leads to $C L N V_{1}=(120 €+(0 €$ $-60 €)-(0 €-20 €)) /(1+0.10)^{1}=80 € / 1.10^{1}=72.73 €$ for customer 1 and $C L N V_{4}=(60 €+(0 €-30 €)-(20 €-0$ $€)) /(1+0.10)^{1}=10 € / 1.10^{1}=9.09 €$ for customer 4 , respectively. Table 2 summarizes the results for the extended model of the CLNV.

Compared to the results of the basic model of the CLNV, on the one hand, the higher CLNV for customer 1 adequately reflects the customer's additional cash flow potential - indeed, without the negative influence of customer 4 , s/he would generate additional cash flows of $20 €$. On the other hand, the lower value for $C L N V_{4}$ represents that due to the negative influence of customer $420 €$ of the additional cash flow potential of customer 1 cannot be realized. Hence, the differences in value of both customers are taken into account and at the same time the sum of the customers' CLNVs (i.e. $C L N V_{1}+C L N V_{2}+C L N V_{3}+$ $\left.C L N V_{4}=240.90 €\right)$ stays the same and still equals the net present value of all cash flows generated by the whole customer base. The latter is important to ensure a consistent customer valuation neither disregarding nor double counting cash flows. 
Table 2 CLNV example (extension of the basic model)

\begin{tabular}{|c|c|c|c|c|}
\hline & Customer 1 & Customer 2 & Customer 3 & Customer 4 \\
\hline Individual cash flows $C F_{i, 1}[€]$ (present value $[€] / C L V_{i}$ ) & $120.00(109.09)$ & $55.00(50.00)$ & $30.00(27.27)$ & $60.00(54.54)$ \\
\hline $\begin{array}{l}\text { Positive influence (basic model) } \Delta \text { network contribution } \\
\quad(\text { positive influence) }[€] \text { (present value }[€])\end{array}$ & $-60.00(-54.55)$ & $0.84(0.75)$ & $89.17(81.07)$ & $-30.00(-27.27)$ \\
\hline $\begin{array}{l}\text { Negative influence (extension) } \Delta \text { network contribution } \\
\quad \text { (negative influence) }[€] \text { (present value }[€])\end{array}$ & $-20.00(-18.18)$ & $0.00(0.00)$ & $0.00(0.00)$ & $20.00(18.18)$ \\
\hline$C F_{i, 1}^{\text {negative_influence }}[€]$ (present value $[€]$ ) & $0.00(0.00)$ & $0.00(0.00)$ & $0.00(0.00)$ & $20.00(18.18)$ \\
\hline$C F_{i, 1}^{\text {negatively_influenced }}[€]$ (present value $[€]$ ) & $20.00(18.18)$ & $0.00(0.00)$ & $0.00(0.00)$ & $0.00(0.00)$ \\
\hline$C L N V_{i}[€]$ & 72.72 & 50.75 & 108.34 & 9.09 \\
\hline
\end{tabular}

\section{Demonstration of the applicability}

In the following, as an essential part of the Design Science research process (Gregor and Hevner 2013; Hevner et al. 2004; Peffers et al. 2007), we demonstrate the practical applicability of our CLNV model.

\section{Setting and dataset}

The European OSN focusing on sports was founded in 2007. It was initially designed as a pure OSN for active and passive sportsmen interested in socializing and communicating about sports related topics like fitness, nutrition, or health. For instance, users discuss sports events like the soccer world cup or compare workout plans. The OSN provides users with basic functions to socialize and interact with each other (i.e., creating user profiles, managing contacts, and sending messages) comparable to other OSNs. One major difference to OSNs such as Facebook is, however, that the OSN did not have a public "wall" at the time of our investigation. The public discussion forums of the OSN under consideration, enabling publicly visible one-to-many distribution of messages, were only rarely used. Rather, the users usually took the opportunity to send private messages to one specific other user within the OSN. Therefore, in the following we focus on this kind of messages. Here, the OSN under investigation provided in form of a private message functionality the possibility for users to establish direct and private one-to-one connections to other users. In 2009, the OSN's operators started an affiliated online shop on a pilot basis selling sports products. The shop was intended as a supplementary area of engagement and as an additional source of revenue besides advertising. During the time frame under consideration, the shop offered selected sports products with attractive discounts exclusively to members of the OSN.

In order to successfully launch and advertise the affiliated shop, the OSN's operators planned to run user specific targeted marketing campaigns. To do so, key users were supposed to be identified, segmented, and addressed based on their customer values. The operators emphasized that besides actual customers purchasing products, users who are actively involved in the OSN and recommend products to other users are also expected to be valuable for the shop. These users were supposed to help the OSN to increase the number of customers by leveraging their direct and indirect influence on other users' purchase decisions. Hence, the classic CLV was not adequate for the required customer valuation. Instead we agreed to consider both direct and indirect network effects by using our CLNV model. Indeed, the OSN and its affiliated shop provide an optimal setting to apply the CLNV model in a real-world case. Having access to both data on user interactions in the OSN and on their actual purchase behavior gives us the rare opportunity to integrate network effects based on influence among (potential) customers into customer valuation. Please note that the focus of the application is on the revenues from the affiliated online shop only, we do not consider revenues from additional sources such as advertising.

We use two datasets including interaction and purchasing data of the OSN and its affiliated shop spanning a nine-month period between July 2009 and March 2010. Consider Table 3 for a description of the datasets. The first dataset comprises all users of the OSN and the messages exchanged among these users in the relevant period including information on the sender, the recipient, and the time stamp. This dataset contains 60,029 users. Overall, 264,017 messages were sent by 5,902 of these users in the period under investigation. The low share of users sending messages is typical for networks such as OSNs and has also been found in prior research (Benevenuto et al. 2009; Wilson et al. 2009). All of the 60,029 users received at least one message. The second dataset contains information about the users purchasing products in the online shop, including the date of the purchases and the corresponding gross contributions. In total, 650 purchases were made by 497 of the 60,029 users. The minimum amount of purchases of these users was one, the maximum was eight. The average gross contribution of a customer's purchase was $49.45 €$, with a maximum of $390 €$. 
Table 3 Description of the datasets ( $n=60,029$ users)

\begin{tabular}{llcl}
\hline Incidence & Totals & Respective users (\% of all users) & Mean per respective user \\
\hline Messages (sent) & 264,017 & $5,902(9.8 \%)$ & 44.73 \\
Messages (received) & 264,017 & $60,029(100.0 \%)$ & 4.40 \\
Purchases & 650 & $497(0.8 \%)$ & 1.31 \\
Gross contribution & $24,577.92 €$ & $497(0.8 \%)$ & $49.45 €$ \\
\hline
\end{tabular}

\section{Application of the customer lifetime network value}

At first, to apply the CLNV all input parameters had to be operationalized based on the available data. To guarantee a reasonable and practicable application, we based our operationalization on both previous research and the discussions with the OSN's operators. When determining the parameters of the model for our application and for illustration purposes we used simplifying assumptions where possible to reduce the complexity and not to distract readers from the proposed model constituting the core of this work. Moreover, we focused on the basic model of the CLNV. On the one hand, due to the fact that the shop was just in its ramp up phase, attracting new customers by leveraging effects of direct and indirect positive social influence (e.g., recommendation of new products and offers to other users of the OSN) seemed particularly important. On the other hand, the granularity and accuracy of the results of the basic model met the requirements of the OSN under consideration.

\section{Determination of the time period t and the expected lifetime of the customer relationship $T$}

We decided to use monthly time periods. Such sub-annual time periods are adequate for the fast-moving, dynamic environment of OSNs and enable a differentiated view on changes in user behavior. This is consistent with previous research (Kumar et al. 2007). In addition, monthly time periods acknowledge the fact that the affiliated shop had just been launched and therefore marketing campaigns to promote the shop were required to be designed and implemented promptly. To determine the expected lifetime $T$ of customer relationships, previous research often uses hazard rate models forecasting the probability of defection or purchase (Helsen and Schmittlein 1993; Jain and Vilcassim 1991). Drawing on historic data, we were able to determine the lifetime of each customer relationship based on his/her historic transaction data.

\section{Determination of the discount rate d}

Discount rates strongly depend on the specific situation and the risks of a company. Therefore, we based our estimation on discussions with the OSN's operators and the affiliated shop. As a result, the monthly discount rate was set to $d=0.008$. This is equivalent to an annual discount rate of $10 \%$ used by the OSN's operators in similar contexts in the past. Furthermore, an annual discount rate of $10 \%$ is consistent with previous research of customer valuation in the context of networks and marketing (Libai et al. 2013; Weinberg and Berger 2011).

\section{Determination of the cash flows $C F_{i, t}$}

The concept of the CLV and also the CLNV are forward looking and require a prediction of future cash flows. For our demonstration of the CLNV, we used historic transaction data as proxy drawing on existing approaches. Analyzing the customers' historic purchasing behavior, we determined the cash flows generated by user $i$ in period $t\left(C F_{i, t}\right)$. While previous research has in fact found historic data on revenues and costs to be good predictors for future revenues and costs (Kumar et al. 2010b), there are also studies raising the question whether historic behavior is a very accurate predictor for prospective behavior (Jain and Singh 2002; Malthouse and Blattberg 2005). As in our paper we do not focus on developing a new method to predict customers' future revenues or costs but propose a generally new customer valuation model and demonstrate its applicability, we chose a simple backward looking perspective using historic data. For future research and application we suggest to include customer-level factors when forecasting revenues and costs, for instance customer demographics, product usage variables (e.g., product categories), marketing activities, and costs of switching to other companies (Jain and Singh 2002; Singh and Jain 2013).

\section{Determination of the share of cash flows tracing back to influence in the network $\alpha$}

The parameter $\alpha$ represents the share of a customer's cash flows which traces back to the influence of other people in the network. Where necessary, this parameter may also be determined on a customer and/or period specific basis. ${ }^{2}$ Thereby, a parameter of $\alpha=0$ implies that a company assesses no share of cash flows to be induced by influence at all. For instance, companies assuming that customers purchase their products independently of each other not being exposed to social influence at all would choose a parameter of 0 . In that case, the results of the CLNV would coincide with the classic CLV. In contrast, a value for $\alpha$ close to 1 implies that a company considers almost all of the generated cash flows to be induced by influence in the network. Thus, companies assuming that purchases primarily rely on social influence would choose such a high value for the parameter $\alpha$. In practice, each company has to determine (e.g., based on analyses of historical data or 
expert estimations) what proportion of the cash flows is accredited to the influence of other users. In case of the OSN under investigation, we used - based on respective discussions with the operators of the OSN - the value $\alpha=0.5$ to reflect that the OSN assessed half of the cash flows generated by customers in the network to be induced by the influence of others. Unfortunately, due to the fact that the affiliated shop was just in its ramp up phase we could not draw on historical data to verify this choice by means of respective data analyses.

\section{Determination of the strength of direct influence $s_{t}^{i \rightarrow j}$}

Literature widely agrees upon the fact that the impact of social influence in OSNs strongly depends on the strength of the connections among users, which can be determined by the number of social interactions such as messages (Cheung and Lee 2010; Heidemann et al. 2010; Hinz et al. 2011; Kane et al. 2014; Kiss and Bichler 2008). In our application, in order to determine the strength of a user $i$ 's direct influence on user $j\left(s_{t}^{i \rightarrow j}\right)$, we focused on the number of potentially purchase relevant private messages sent from user $i$ to user $j$. Conversely, the strength of influence other users $j$ have on him/her was estimated using the number of potentially purchase relevant private messages $\mathrm{s} / \mathrm{he}$ received $\left(s_{t}^{j \rightarrow i}\right)$. Thereby, analyzing the chronology of purchases and messages on a daily basis, each message within a time frame of 10 days before a purchase in period $t$ was considered as potentially relevant for this purchase. For a better comparison of the influence of different time frames, the results for the time frames of 5 and 7 days can be found in the appendix (cf. Appendix 2). We considered therefore the fast-moving nature of online interactions and focused on private messages as the primary means of communication within the OSN. Being aware that correlation does not imply causation, the fact that we indeed observed a positive correlation $(p$-value $<0.01)$ between the number of messages and purchases may, however, also support our operationalization of the strength of influence to a certain extent. Since in case of our sports OSN no other relevant interactions besides private messages were observed, we considered no other forms of interaction. However, when significant interactions beside private messages occur and may influence customers' purchase behavior in other contexts, these should be considered analogously. For public discussion forums, for instance, the strength of influence can be determined based on the number of posts. Nonetheless, different forms of interactions have to be assessed regarding their influence potential. For example, a post in a public discussion forum may reach various recipients; however, the strength of influence of such a public post on a single recipient may significantly differ from the strength of influence of a private message personally addressing him/her. We also want to point out that regarding the quantification of the strength of influence $s_{t}^{i \rightarrow j}$ between users there may be other relevant aspects beside the mere number of messages sent within a certain time frame like user characteristics, personality, degree of connectivity, or the content of the conversation (Kumar et al. 2010a; Nitzan and Libai 2011; Wang et al. 2014).

\section{Calculation of the CLNV}

Finally, we calculated the CLNV for each user. Analogous to prestige- and eigenvector-related centrality measures the CLNVs can be determined solving the respective system of equations containing one equation per customer $i$ in the network (cf. Eq. (4)) via eigenvector analysis. To do so, we used the power iteration method (cf. e.g., Golub and van Loan 2012) in the software package "NetworkX" for the exploration and analysis of networks and network algorithms (Hagberg et al. 2008). ${ }^{3}$ The power iteration method can be used for calculating the eigenvector of sparse matrices and is known to converge fast (Lin and Cohen 2010). To ensure convergence of the power iteration method the iteration stops when the difference between the computed vectors is smaller than an error tolerance (error tolerance is defined as the number of nodes in the graph $\times 1.0^{-15}$ ) or alternatively after a maximum of 100 iterations. This configuration of the algorithm turned out to be sufficient for an adequate approximation. Using our software implementation, the CLNV was calculated for all 60,029 users. For the 1,978 users with a positive $\mathrm{CLNV}^{4}$ Table 4 provides an overview of the results considering the CLNV as well as its main components. On average, the present value of individual cash flows accounts for $11.95 €$. Due to the design of our model, the two opposing components, $C F_{i, t}^{\text {influence }}$ and $C F_{i, t}^{\text {influenced }}$, balance each other leading to an average present value of $\Delta$ network contribution of $0 €$. However, the present value of $\Delta$ network contribution varies substantially between $-86.98 €(-50 \%$ of the particular user's present value of the generated cash flows) and $372.62 €(+500 \%$ of the particular user's present value of the generated cash flows). Most of the divergence results from the variance of users influencing other users $\left(C F_{i, t}^{\text {influence }}\right)$. Taking all components together, the average $C L N V_{i}$ accounts for $11.95 €$, with a minimum of $0.01 €$ and a maximum of $447.16 €$. Thus, as designed in the model, the average CLNV coincides with the average present value of individual cash flows, since the CLNV reallocates cash flows but does not change the overall present value of the network of 23,633.50€. 1,978 users have a positive CLNV and therefore a positive value for the affiliated shop of the OSN. These are about $398 \%$ more users than the 497 customers that actually purchased products in the period under investigation.

\footnotetext{
${ }^{3}$ Vgl. http://networkx.github.io/

${ }^{4}$ Results for the CLNV below $0.01 €$ were rounded to zero.
} 
Table 4 Results of the application ( $n=1,978$ Users)

\begin{tabular}{|c|c|c|c|c|}
\hline & Mean & Minimum & Maximum & Standard deviation \\
\hline Individual cash flows $C F_{i, 1}[€]$ (present value $[€] / C L V_{i}$ ) & $13.15(11.95)$ & $0.00(0.00)$ & $418.65(380.59)$ & $33.21(30.19)$ \\
\hline$\Delta$ network contribution $[€]$ (present value $[€]$ ) & $0.00(0.00)$ & $-95.68(-86.98)$ & $409.88(372.62)$ & $14.99(13.63)$ \\
\hline$C F_{i, 1}^{\text {influence }}[€]$ (present value $[€]$ ) & $3.01(2.74)$ & $0.00(0.00)$ & $901.76(819.78)$ & $27,59(25.08)$ \\
\hline$C F_{i, 1}^{\text {influenced }}[€]$ (present value $[€]$ ) & $3.01(2.74)$ & $0.00(0.00)$ & $491.88(447.16)$ & $16.26(14.78)$ \\
\hline $\mathrm{CLNV}_{\mathrm{i}}[€]$ & 11.95 & 0.01 & 447.16 & 30.27 \\
\hline
\end{tabular}

\section{Findings of the application and novel user segmentation}

For the discussion of the findings of the application, we compare the CLNV with the classic CLV and study the impact of direct and indirect network effects. In addition, based on the results, we propose a novel user segmentation. Note that in the following we refer to the 1,978 users with a positive CLNV.

\section{Discussion of the findings of the customer lifetime network value}

The findings of the application of the CLNV are analyzed in three ways. First, we compare the absolute values of the CLNV and the classic CLV. For both the overall sum is 23,633.50€. The CLNV, however, alters the allocation of value among users compared to the classic CLV. In fact, we observe a significant difference $(p$-value $<0.001)$ between the CLNV and the classic CLV. Further, we observe on the one hand that for about $77.7 \%(1,536)$ of the users the CLV accounts for less than the CLNV. Thus, the value of these users would be underestimated when ignoring network effects and the OSN might spend insufficient resources on them. Moreover, due to a lack of purchases about $96.4 \%(1,481)$ of these underestimated users would even be completely ignored in marketing campaigns based on the classic CLV although being valuable for the OSN as their influence induces cash flows of other customers. On the other hand, for about $6.5 \%$ (128) the classic CLV accounts for more than the CLNV. When ignoring network effects, the OSN would overestimate the value of these users and might therefore spend too many resources on them.

Second, we compare the relative importance of users and ranked all 1,978 users once based on the CLNV and once based on the classic CLV. Depending on these rankings, we identified the top users (top 1\%-users, top 10\%-users, top $20 \%$-users, top 30\%-users) for each approach. Table 5 displays the number of users per top user group according to the CLNV and the number of users who are not included in the respective top user group when considering the classic CLV. For example, $30.0 \%$ of the top $1 \%$-users regarding the
CLNV are ranked in a lower top user group regarding the classic CLV. Some of them are not even within the top 20\%users regarding the classic CLV. Hence, parts of the highly valuable users according to the CLNV would be completely ignored and resources might be spent in a less efficient way when designing a top user marketing campaign based merely on the CLV. Taking a look at the top $20 \%$-users regarding the CLNV, around $10.4 \%$ are not among the top $20 \%$-users and around $17.1 \%$ are not even assigned to the top $30 \%$-users regarding the CLV. In consequence, classic marketing campaigns might focus on the "wrong" users while neglecting more valuable ones.

Third, we analyze the impact of direct and indirect network effects. Indeed, we observe a significant difference ( $p$-value $<0.001$ ) between the CLNV including both direct and indirect network effects and the CLNV including only direct network effects (cf. Klier et al. 2014). In fact, for about $81.2 \%(1,607)$ of the users the value differs when neglecting the indirect network effects. Thus, most of the users would be misvalued when solely considering direct network effects. In terms of numbers, this misvaluation indeed plays a central role: We observe a major difference between the sums of network effects based on direct influence $(2,820.65 €)$ and both direct and indirect influence $(5,425.59 €)$. Hence, almost $48.0 \%$ of all induced cash flows can be traced back to indirect influence, illustrating the importance of considering indirect network effects in customer valuation.

Table 5 Comparison of top user groups for the CLNV and the CLV ( $n=1,978$ users)

\begin{tabular}{lll}
\hline Top user group & $\begin{array}{l}\text { Number of users } \\
\text { per respective top } \\
\text { user group regarding } \\
\text { the CLNV }\end{array}$ & $\begin{array}{l}\text { Number of users } \\
\text { not included in the } \\
\text { respective top } \\
\text { user group regarding } \\
\text { the CLV }\end{array}$ \\
\hline Top 1\%-users & 20 & $6(30.0 \%)$ \\
Top 10\%-users & 198 & $18(9.1 \%)$ \\
Top 20\%-users & 396 & $41(10.4 \%)$ \\
Top 30\%-users & 593 & $67(11.3 \%)$ \\
\hline
\end{tabular}


Taken together, we argue that it is very important to include both direct and indirect network effects in customer valuation. Even with the rather exemplary dataset of the OSN's affiliated shop during its ramp up phase, we observed significant differences between the CLNV and the CLV. Nevertheless, it has to be noted that on basis of the real-world example we can only demonstrate the practical applicability of our approach but do not prove that the CLNV really improves efficiency regarding the way how marketing resources are spent in practice. However, we are confident that our proposed model may help to establish and maintain valuable customer relationships for example by focusing on the actually important top user groups.

\section{Novel user segmentation based on the CLNV}

The operators of the OSN intended to use the CLNV to design targeted marketing campaigns and improve advertising for the affiliated shop. In order to support these efforts, we defined distinct CLNV-based user segments and derived selected marketing goals for each segment (Kumar et al. 2007). However, it is important to note that the exemplary user segmentation presented here is only one potential use case of the application of the CLNV besides many others like enabling a valueoriented customer relationship management where the "true" customer value is needed to support decision making (e.g., in the context of customer acquisition or customer retention).

Inspired by the CLNV as segmentation criteria we used the CLNV's two main components (cf. summands in the formula in the subsection "Basic Idea") present value of individual cash flows and present value of $\Delta$ network contribution (cf. Fig. 3).

Fig. 3 CLNV-based user segments ( $n=1,978$ users)
The first criterion is subdivided into the two degrees high and low, split by the arithmetic mean (11.95€) of the present value of individual cash flows. User segments that score high on the criterion present value of individual cash flows are named Champions and the ones scoring low Misers (Kumar et al. 2007). The second criterion is subdivided into the three degrees positive, zero, and negative with respect to the present value of $\Delta$ network contribution. Depending on the score of the second criterion, we refer to the Champions as Influencing Champions (i.e., users with a positive present value of $\Delta$ network contribution), Classic Champions (i.e., users with zero present value of $\Delta$ network contribution), and Influenced Champions (i.e., users with a negative present value of $\Delta$ network contribution). Analogously, we define the segments that score low on the first criterion as Influencing Misers, Classic Misers, and Influenced Misers. The size of the segments and their average CLNV are presented in Fig. 3. We can draw two main findings from the proposed user segmentation: First, the average CLNV varies substantially between the six segments, from $47.99 €$ (Influencing Champions) to $0.36 €$ (Classic Misers). Note that the low value of the latter, and of the Misers in general, can be explained by their average present value of individual cash flows being close to $0 €$. In contrast, the Influencing Champions both influence other customers and at the same time make purchases, thus classifying as the most valuable segment. Second, the distribution of users across the six segments varies considerably. About $66.0 \%(1,305)$ of the users are classified as Influencing users. Thereby, solely about $1.3 \%$ (25) of the users perform well on both criteria, thus are assigned to the segment of Influencing Champions. Most users, in fact almost $64.7 \%$ (1,280), are segmented as Influencing Misers. Thus, they rarely make purchases, but mainly induce other users' cash flows. Note that regarding their CLV most of these users would be classified as invaluable and completely ignored in marketing campaigns. In

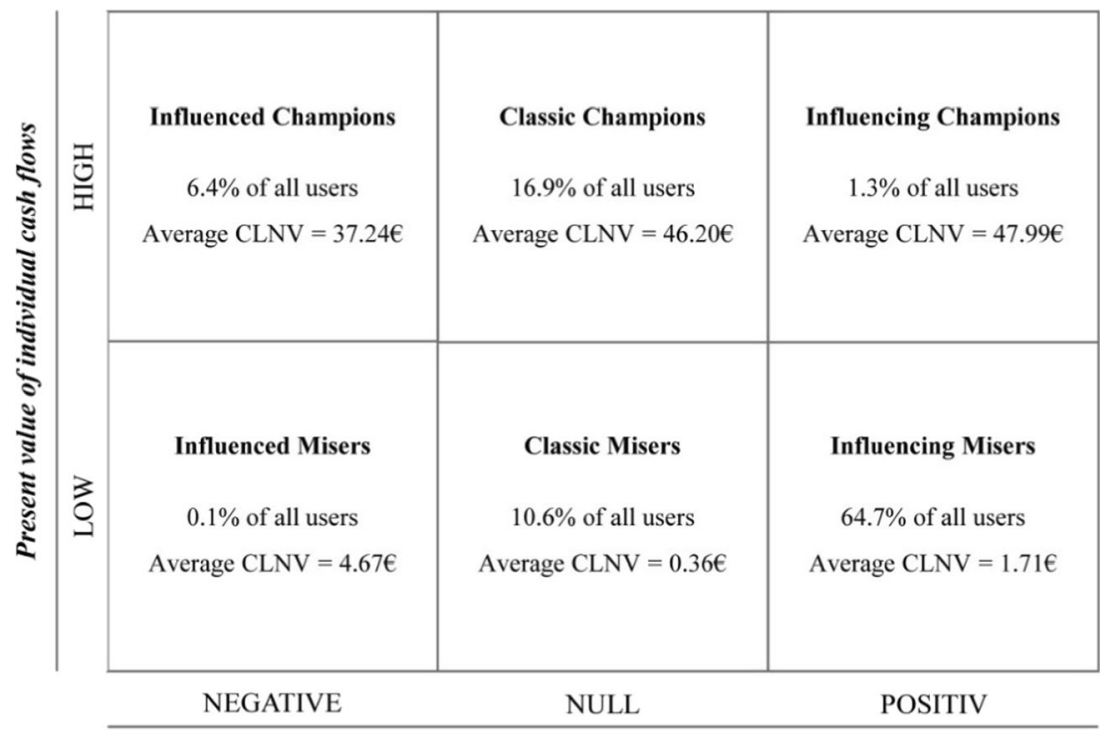

Present value of $\Delta$ network contribution 
contrast to the huge amount of Influencing users, less than $6.5 \%$ (128) of all users are classified as Influenced users. In particular, $6.4 \%$ (127) are assigned to the segment of Influenced Champions, thus they make purchases that are mainly induced by the influence of others. Merely $0.1 \%$ (1) belongs to the segment of Influenced Misers. Hence, we observe a large group of users (Influencing users) influencing a substantial smaller group of customers (Influenced users). This is due to the shop being in its ramp up phase with a rather modest number of purchases. Finally, around $28.5 \%$ (545) of the users are classified as Classic users, thus show no network effects at all. Thereby, almost $16.9 \%$ (334) belong to the segment of Classic Champions, while around $10.6 \%$ (211) are assigned to the segment of Classic Misers. Taken together, we identify substantial potential to improve the users' value by moving all other segments to Influencing Champions. Thus, we propose to aim for (1) turning Misers into Champions and (2) moving users from Classic and Influenced to Influencing users. In particular, the OSN should focus on the large segment of Influencing Misers and move them towards Influencing Champions.

Based on this user segmentation, we proposed a strategic marketing campaign. Thereby, we determined the reasonable investment for each segment by comparing the user's present CLNV with the intended CLNV. For illustration, selected marketing efforts for each segment are briefly sketched in the following. ${ }^{5}$

\section{Influencing Misers}

To increase the present value of individual cash flows of Influencing Misers, by this means turning them into Influencing Champions, these users should be encouraged to increase individual purchases. As an example: For products other users bought as result of their recommendation, discounts could be offered to them. Such discounts could be complemented by an e-mail thanking for recommending the shop's product.

\section{Influenced Champions and Classic Champions}

To turn Classic and Influenced Champions into Influencing Champions, these users should be encouraged to actively exert influence on others. This could be achieved, for instance, by sending an e-mail after each purchase of Classic or Influenced Champions offering monetary rewards for a successful recommendation. In addition, e-mails to Influenced Champions could refer to the positive experiences with recommendations they received themselves.

\footnotetext{
$\overline{5}$ Please note that, while the presented user segmentation seems suitable for a first hand classification of users in relation to other users, an in-depth analysis as well as a long-term application of the segmentation should also put a stronger focus on absolute values.
}

Influenced and Classic Misers

Moving Influenced and Classic Misers towards the segment of Influencing champions requires increasing their amount of both purchases and recommendations. Thus, such users could be targeted by combining the marketing actions described above, i.e., offering monetary incentives for both purchasing products and using their influence to induce other users' purchases in the OSN's affiliated shop.

\section{Conclusion, limitations and further research}

\section{Contribution to research and practice}

We propose a novel customer valuation model incorporating an integrated network perspective, referred to as the CLNV. The CLNV determines the value of a customer based on the present value of the individual cash flows generated by him/ her through purchases and a network component reflecting the present value of his/her net contribution to the network considering the entire network structure. The practical applicability of the basic model of the CLNV was exemplary demonstrated using a real-world dataset of a European OSN focusing on sports. The proposed model aims at allowing companies to evaluate their customers in the context of OSNs by enabling the assessment of the "true value" of a customer considering his/her social influence on other members of the network. Overall, the contribution to theory and practice is threefold:

First, the CLNV enables a well-founded valuation of individual customers: By taking an integrated network perspective that considers mirror-imaged network effects both for customers influencing others and customers that are influenced, the CLNV ensures a correct individual valuation of all customers in two ways. On the one hand a customer's value is not limited to his/her individual purchases but increased when $\mathrm{s} / \mathrm{he}$ induces cash flows of others by his/her influence. On the other hand, by decreasing the value of a customer if his/her cash flows are induced by the influence of others, the customer's value is assessed more adequately and is not overestimated as in the classic CLV (Adamic and Adar 2003; Berger and Nasr 1998; Guetzkow 1951) and in previous models considering network aspects (Kumar et al. 2007, 2010a, b; Weinberg and Berger 2011). Keeping both effects in mind, in our application we observed significant differences between the CLNV and the CLV. Both effects have a practical influence on decision making and are crucial for operators as, for example, "[f]ailure to 
include these social effects could lead to misallocation of scarce marketing resources" (Hogan et al. 2003, p. 197): On the one hand, without the CLNV customers who increase profits of a company mainly by influencing others would be ignored in marketing campaigns. On the other hand, the CLNV helps companies to avoid marketing to unprofitable customers who fail to generate own or induce other customers' cash flows.

Second, the CLNV allows an allocation of not only direct but also indirect influence. Since influence in networks spreads virally through the entire customer network, indirect influence has to be considered when valuating customers in networks. Therefore, inspired by prestige- and eigenvector-related centrality measures the CLNV includes an iterative component, enabling the incorporation of influence among all degrees of separation. Consequently, in contrast to most of the existing methods (Klier et al. 2014), the CLNV allows for a full network approach altering customer valuation substantially. In fact, in our demonstrative application we observed a significant impact of indirect effects on the value of customers, thereby underlining the practical relevance of our approach. Hence, the CLNV contributes to customer valuation in two ways: On the one hand, the CLNV avoids underestimating the value of customers who spread influence inside a network. On the other hand, the CLNV avoids overestimating the value of customers who are the intermediaries of the former. Hence, based on the results of the CLNV, a more effective spending of existing marketing budget can be achieved.

Third, the CLNV enables a sound determination of a company's CE: Our model is the first to contain direct as well as indirect network effects and ensures at the same time a sound determination of a company's CE by aggregating individual customer values. Key to this is our integrated network perspective ensuring that network effects are not double counted. Double counting is a serious issue since previous models tend to overestimate the company's CE as they count induced values twice, once for the customer whose social influence induces purchases and once for the customer generating them. Thereby, decision makers are forced to calculate CE based solely on the classic CLV: only "[...] keeping CLV and CRV separate ensures that 'double counting' of cash flows is avoided" (Weinberg and Berger 2011, p. 332). Hence, when assessing a company's CE, decision makers should use the CLNV to avoid wrong strategic customer decisions (e.g., acquisition of new customers or bounding of existing ones at too high costs).
Taken together, the CLNV provides a novel and accurate approach for customer valuation in context of network effects. Building on this, we exemplary demonstrated a new and well-founded user segmentation based on the CLNV's two main components present value of individual cash flows and present value of $\Delta$ network contribution. This segmentation extends both the informative content of segmentation based on the classic CLV and the segmentation based on previous models considering network effects (not accounting for indirect effects and negative net network contributions). Thus, applied in practice, the segmentation based on the CLNV may help companies to design better marketing campaigns.

\section{Limitations and further research}

Our model is subject to limitations which - to a certain extent - also serve as promising starting points for future research. First, by means of the real-world case of the European OSN we could demonstrate the practical applicability of the basic model of the CLNV. However, we could not prove superiority of the new approach regarding improved efficiency with respect to the way how marketing resources are spent nor could we prove that the redistribution of the discounted cash flows as proposed by the model really reflects the "true" impact on buying decisions in practice. Evaluating or proving this practical superiority would require a field experiment. Unfortunately, with the OSN focusing on sports we were not able to conduct such an experiment. For future research we are in contact with two companies from the banking and insurance sector which are highly interested in an application of the CLNV model. We hope that we will be able to conduct such a field experiment to substantiate the practical evaluation of our approach including the extension of the basic model considering negative influence in the future.

Second, when determining the parameters of the basic model in our application and for illustration purposes we used simplifying assumptions where possible to reduce the complexity and to keep the focus on the proposed model. For example, we determined the strength of influence $s_{t}^{i \rightarrow j}$ between users based on the mere number of messages sent within a certain time frame. In doing so, like many prestige- and eigenvector-related centrality measures (e.g. classical PageRank algorithm) we disregard other relevant aspects like the content of the conversation which may be used to determine much more precisely the strength of influence $s_{t}^{i \rightarrow j}$ or would help to determine a sort of "success rate" whether a certain purchase was actually triggered 
by a message of another user or not. Without any doubt, the appropriate determination of the parameters of the model for the underlying context of application poses a major challenge regarding the practical applicability. To approach this issue, it seems particularly promising to make use of contributions in the emerging research strand of Social Media Analytics (von Stieglitz et al. 2014). With the help of advanced text mining and sentiment analysis techniques (Gamon et al. 2005; Hu and Liu 2004; Pang and Lee 2008), for example, content of user interactions may be distinguished between (particularly) relevant vs. non-relevant, positive vs. negative, etc. to further refine the results in the future.

Third, in the basic model and the practical application of our approach we focused on positive social influence and did not include the effect of potentially negative social influence, for example in form of negative WOM. To alleviate this issue to a certain extent, we proposed an extension of the basic model considering both positive and negative social influence. In this context, however, it has to be noted that the determination of the parameters of the extended model is even more challenging compared to the basic model. Indeed, it is no longer sufficient to estimate individual customers' real cash flows but also the individual customers' imaginary cash flows that cannot be realized due to negative social influence of other customers. Actually, the latter seem particularly difficult to grasp and may only be roughly estimated.

Fourth, OSNs are never "closed systems" and WOM outside electronic networks is of major importance as well (Berger 2014). Against this background, focusing on the online world when calculating the CLNV can only provide a limited view and may be insufficient in some cases. Therefore, we see the integrated quantification of both online and offline influence as a very promising topic for future research (Liu et al. 2012; Scarpi et al. 2014). This seems particularly challenging due to the fact that for the context of OSNs it is much easier to determine and estimate the customer specific parameters of the CLNV in an automated way (Tang and Guo 2015) (e.g., based on messages exchanged electronically and using text mining and sentiment analysis techniques and algorithms).

Finally, we focused on social influence on present customers assuming the customer network to be stable. Including growth of customer networks into valuation could be another interesting journey for further research.

We hope that our paper contributes to a better understanding of customer valuation in the context of network effects and stimulates further research in this exciting field.

\section{Appendix 1}

Table 6 Overview of the mathematical notations

\begin{tabular}{ll}
\hline Mathematical notation & Description \\
\hline$C F_{i, t} \in \mathfrak{R}$ & Cash flows generated individually by customer $i$ in period $t$. \\
$C F_{i, t}^{\text {influence }} \in \mathfrak{R}$ & Cash flows of customers induced by the direct and indirect \\
& positive influence of customer $i$ in period $t$. \\
$C F_{i, t}^{\text {influenced } \in \mathfrak{R}}$ & Cash flows of customer $i$ induced by the direct and indirect positive \\
& influence of other customers in period $t$. \\
$C F_{i, t}^{\text {negative_influence }}$ & Cash flow potential of other customers that cannot be realized in period $t$ \\
$C F_{i, t}^{\text {negatively_influenced }}$ & due to direct or indirect negative influence of customer $i$. \\
Influenced $(i, t)$ & Cash flow potential of customer $i$ that cannot be realized in period $t$ due to \\
Influence $(j, t)$ & negative influence of other customers on customer $i$. \\
$T \in \mathbb{N}$ & Set of customers directly influenced by customer $i$ in period $t$. \\
$d \in \mathfrak{R}^{+}$ & Set of customers exerting direct influence on customer $j$ in period $t$. \\
$s_{t}^{i \rightarrow j} \in \mathfrak{R}$ & Expected lifetime of the customer relationship. \\
$\alpha \in[0,1[$ & Discount rate. \\
\hline
\end{tabular}




\section{Appendix 2}

We additionally carried out the calculation of the CLNV for the time frame of 5 days (cf. Tables 7 and 8, Fig. 4) and the time frame of 7 days (cf. Tables 9 and 10, Fig. 5).

Table 7 Results of the application (time frame $=5$ days, $n=1,287$ users)

\begin{tabular}{|c|c|c|c|c|}
\hline & Mean & Minimum & Maximum & Standard deviation \\
\hline Individual cash flows $C F_{i, 1}[€]$ (present value $[€] / C L V_{i}$ ) & $21.66(19.69)$ & $0.00(0.00)$ & $418.65(380.59)$ & $40.42(36.74)$ \\
\hline$\Delta$ network contribution $[€]$ (present value $[€]$ ) & $0.00(0.00)$ & $-65.30(-59.37)$ & $285.79(259.81)$ & $12.74(11.58)$ \\
\hline$C F_{i, 1}^{\text {influence }}[€]$ (present value $[€]$ ) & $3.21(2.92)$ & $0.00(0.00)$ & $571.57(519.61)$ & $22.30(20.27)$ \\
\hline$C F_{i, 1}^{\text {influenced }}[€]$ (present value $\left.[€]\right)$ & $3.21(2.92)$ & $0.00(0.00)$ & $285.79(259.81)$ & $13.71(12.46)$ \\
\hline$C L N V_{i}[€]$ & 19.69 & 0.01 & 380.59 & 35.98 \\
\hline
\end{tabular}

Table 8 Comparison of top user groups for the CLNV and the CLV (time frame $=5$ days, $n=1,287$ users)

\begin{tabular}{lll}
\hline Top user group & $\begin{array}{l}\text { Number of users } \\
\text { per respective top } \\
\text { user group regarding } \\
\text { the CLNV }\end{array}$ & $\begin{array}{l}\text { Number of users } \\
\text { not included in the } \\
\text { respective top user } \\
\text { group regarding } \\
\text { the CLV }\end{array}$ \\
\hline Top 1\%-users & 12 & $2(16.7 \%)$ \\
Top 10\%-users & 120 & $16(13.3 \%)$ \\
Top 20\%-users & 240 & $20(8.3 \%)$ \\
Top 30\%-users & 360 & $26(7.2 \%)$ \\
\hline
\end{tabular}

Fig. 4 CLNV-based user segments (time frame $=5$ days, $n=1,287$ users $)$

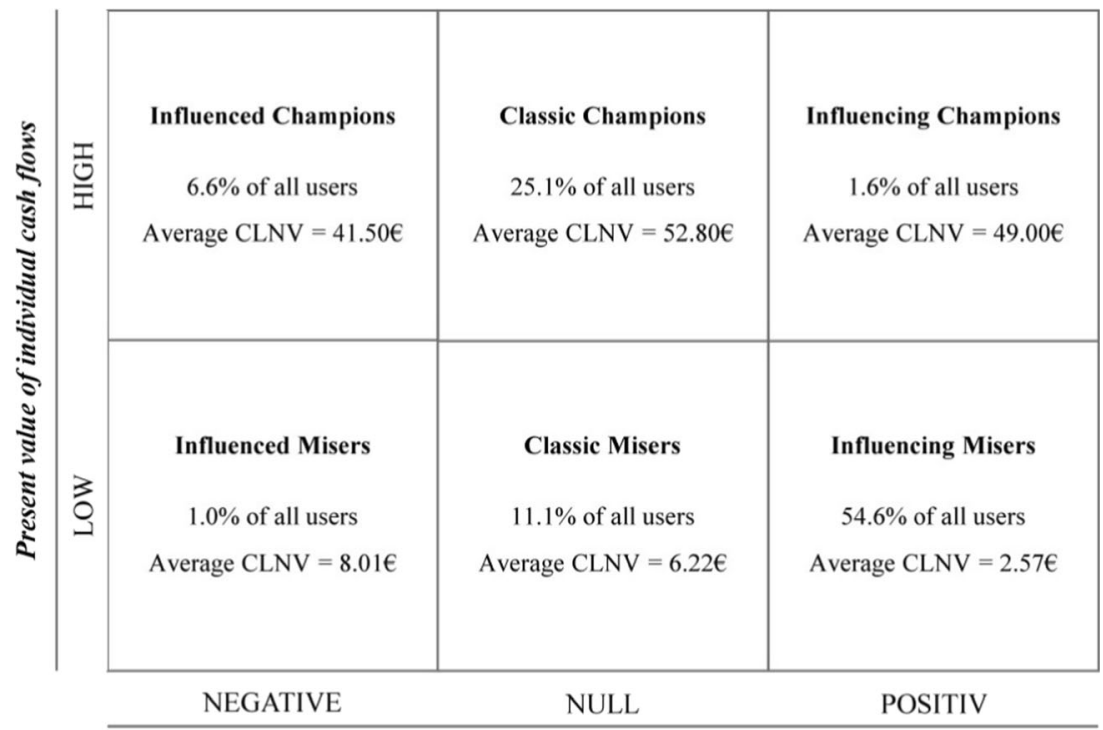

Present value of $\Delta$ network contribution 
Table 9 Results of the application (time frame $=7$ days, $n=1,470$ users)

\begin{tabular}{|c|c|c|c|c|}
\hline & Mean & Minimum & Maximum & Standard deviation \\
\hline Individual cash flows $C F_{i, 1}[€]$ (present value $[€] / C L V_{i}$ ) & $12.76(11.60)$ & $0.00(0.00)$ & $340.88(309.44)$ & $28.28(25.71)$ \\
\hline$\Delta$ network contribution $[€]$ (present value $[€]$ ) & $0.00(0.00)$ & $-51.29(-46.62)$ & $216.16(196.51)$ & $9.81(8.92)$ \\
\hline$C F_{i, 1}^{\text {influence }}[€]$ (present value $\left.[€]\right)$ & $2.31(2.10)$ & $0.00(0.00)$ & $432.32(393.02)$ & $17.43(15.85)$ \\
\hline$C F_{i, 1}^{\text {influenced }}[€]$ (present value $\left.[€]\right)$ & $2.31(2.10)$ & $0.00(0.00)$ & $216.16(196.92)$ & $9.15(9.75)$ \\
\hline$C L N V_{i}[€]$ & $(11.60)$ & $(0.01)$ & $(309.44)$ & $(25.29)$ \\
\hline
\end{tabular}

Table 10 Comparison of top user groups for the CLNV and the CLV (time frame $=7$ days, $n=1,470$ users)

\begin{tabular}{lll}
\hline Top user group & $\begin{array}{l}\text { Number of users } \\
\text { per respective } \\
\text { top user group regarding the } \\
\text { CLNV }\end{array}$ & $\begin{array}{l}\text { Number of users } \\
\text { not included in } \\
\text { the respective } \\
\text { top user group } \\
\text { regarding the CLV }\end{array}$ \\
\hline Top 1\%-users & 15 & $4(26.7 \%)$ \\
Top 10\%-users & 147 & $17(11.6 \%)$ \\
Top 20\%-users & 294 & $29(9.9 \%)$ \\
Top 30\%-users & 441 & $21(4.8 \%)$ \\
\hline
\end{tabular}

Fig. 5 CLNV-based user segments (time frame $=7$ days, $n=1,470$ users)

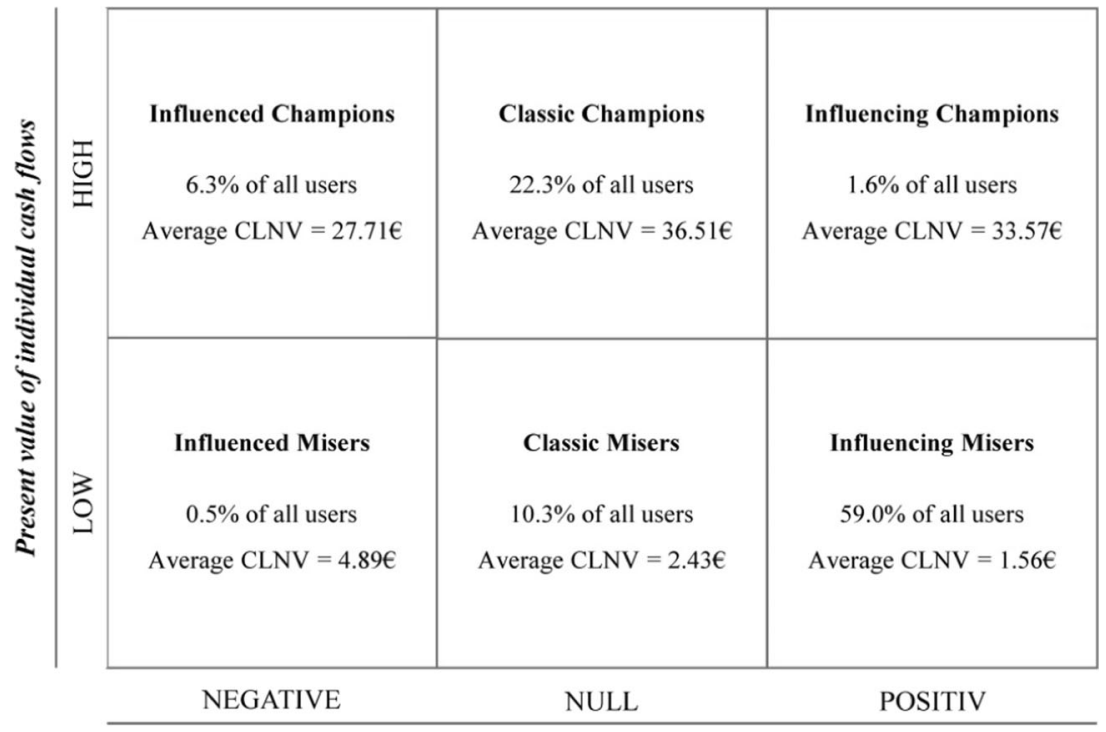

Present value of $\Delta$ network contribution

\section{References}

Adamic, L. A., \& Adar, E. (2003). Friends and neighbors on the web. Social Networks, 25(3), 211-230.

Algesheimer, R., \& von Wangenheim, F. (2006). A network based approach to customer equity management. Journal of Relationship Marketing, 5(1), 39-57.

Aral, S., \& Walker, D. (2012). Identifying influential and susceptible members of social networks. Science, 337(6092), 337-341.
Arndt, J. (1967). Role of product-related conversations in the diffusion of a new product. Journal of Marketing Research, 4(3), 291-295.

Asch, S. E. (1951). Effects of group pressure upon the modification and distortion of judgements. In H. Guetzkow (Ed.), Groups, Leadership and men. Research in human relations (pp. 222-236). Oxford: Carnegie Press.

Bampo, M., Ewing, M. T., Mather, D. R., Stewart, D., \& Wallace, M. (2008). The effects of the social structure of digital networks on viral marketing performance. Information Systems Research, 19(3), 273290. 
Benevenuto, F., Rodrigues, T., Cha, M., \& Almeida, V. (2009). Characterizing user behavior in online social networks. In Proceedings of the 9th ACM SIGCOMM Conference on Internet Measurement (pp. 49-62). Chicago.

Berger, J. (2014). Word of mouth and interpersonal communication: a review and directions for future research. Journal of Consumer Psychology, 24(4), 586-607.

Berger, P. D., \& Nasr, N. I. (1998). Customer lifetime value: marketing models and applications. Journal of Interactive Marketing, 12(1), $17-30$.

Bonacich, P. (1972). Factoring and weighting approaches to status scores and clique identification. Journal of Mathematical Sociology, 2(1), $113-120$.

Bond, R. M., Fariss, C. J., Jones, J. J., Di Kramer, A., Marlow, C., Settle, J. E., \& Fowler, J. H. (2012). A 61-million-person experiment in social influence and political mobilization. Nature, 489(7415), 295 298.

Brin, S., \& Page, L. (1998). The anatomy of a large-scale hypertextual web search engine. Computer Networks and ISDN Systems, 30(17), 107-117.

Butler, R. A. (2017). How millennial consumers make buying decisions. https://reneeannbutler.com/2017/02/02/how-millennial-consumersmake-buying-decisions/. Accessed 03 Feb 2017.

Chen, Y., \& Xie, J. (2008). Online Consumer review: word-of-mouth as a new element of marketing communication mix. Management Science, 54(3), 477-491.

Cheung, C. M., \& Lee, M. K. (2010). A theoretical model of intentional social action in online social networks. Decision Support Systems, 49(1), 24-30.

de Valck, K., van Bruggen, G. H., \& Wierenga, B. (2009). Virtual communities: a marketing perspective. Decision Support Systems, 47(3), 185-203.

Domingos, P., \& Richardson, M. (2001). Mining the network value of customers. In Proceedings of the 7th ACM SIGKDD International Conference on Knowledge Discovery and Data Mining (pp. 57-66). San Francisco.

Dwyer, F. R. (1997). Customer lifetime valuation to support marketing decision making. Journal of Interactive Marketing, 11(4), 6-13.

Eccleston, D., \& Griseri, L. (2008). How does web 2.0 stretch traditional influencing patterns? International Journal of Market Research, 50(5), 591-616.

eMarketer. (2014). Worldwide internet, social network and mobile users: Q2 2014 complete forecast. https://drive.google.com/file/d/0B6 dNgmEOnbVhaGd1d0FHVjhlZWM/edit?pli=1. Accessed 03 Feb 2017

eMarketer. (2016). Number of social network users worldwide from 2010 to 2020. http://www.statista.com/statistics/278414/number-ofworldwide-social-network-users/. Accessed 03 Feb 2017.

Erchul, W. P., \& Raven, B. H. (1997). Social power in School consultation: a contemporary view of French and Raven's bases of power model. Journal of School Psychology, 35(2), $137-171$

Freeman, L. C. (1979). Centrality in social networks: conceptual clarification. Social Networks, 1(3), 215-239.

Friedman, T. L. (2013). It's a 401(k) World. http://www.nytimes. com/2013/05/01/opinion/friedman-its-a-401k-world.html. Accessed 03 Feb 2017.

Gamon, M., Aue, A., Corston-Oliver, S., \& Ringger, E. (2005). Pulse: mining customer opinions from free text. In A. F. Famili, J. N. Kok, J. M. Peña, A. Siebes, \& A. Feelders (Eds.), Lecture notes in computer science. Advances in intelligent data analysis VI (pp. 121132). Berlin: Springer.

Ganley, D., \& Lampe, C. (2009). The ties that bind: Social network principles in online communities. Decision Support Systems, 47(3), 266-274.
Gartner Group. (2015). Gartner CMO Spend Survey 2015-2016: digital marketing comes of age. http://gartnerformarketers. com/CMOspend. Accessed 03 Feb 2017.

Gladwell, M. (2000). The tipping point: how little things can make a big difference. Boston: Little, Brown and Company.

Goldenberg, J., Han, S., Lehmann, D. R., \& Hong, J. W. (2009). The role of hubs in the adoption process. Journal of Marketing, 73(2), 1-13.

Golub, G. H., \& van Loan, C. F. (2012). Matrix computations (Vol. 3). Baltimore: JHU Press.

Granovetter, M. S. (1973). The strength of weak ties. American Journal of Sociology, 78(6), 1360-1380.

Granovetter, M. S. (1978). Threshold models of collective behavior. American Journal of Sociology, 83(6), 1420-1443.

Gregor, S., \& Hevner, A. R. (2013). Positioning and presenting design Science research for maximum impact. MIS Quarterly, 37(2), 337355.

Gruzd, A., \& Wellman, B. (2014). Networked influence in social media: introduction to the special issue. American Behavioral Scientist, 58(10), 1251-1259.

Guetzkow, H. (Ed.). (1951). Groups, leadership and men: research in human relations. Oxford: Carnegie Press.

Gupta, S., Hanssens, D., Hardie, B., Kahn, W., Kumar, V., Lin, N., et al. (2006). Modeling customer lifetime value. Journal of Service Research, 9(2), 139-155.

Hagberg, A. A., Schult, D. A., \& Swart, P. J. (2008). Exploring network structure, dynamics, and function using NetworkX. In G. Varoquaux, T. Vaught, \& J. Millman (Eds.), Proceedings of the 7th Python in Science Conference (pp. 11-15). Pasadena.

Harary, F., Norman, R. Z., \& Cartwright, D. (1965). Structural models: an introduction to the theory of directed graphs. New York: John Wiley \& Sons.

Heidemann, J., Klier, M., \& Probst, F. (2010). Identifying key users in online social networks: A PageRank based approach. In Proceedings of the 31st International Conference on Information Systems. St. Louis.

Helsen, K., \& Schmittlein, D. C. (1993). Analyzing duration times in marketing: evidence for the effectiveness of hazard rate models. Marketing Science, 12(4), 395-414.

Herr, P. M., Kardes, F. R., \& Kim, J. (1991). Effects of word-of-mouth and product-attribute information on persuasion: an accessibilityDiagnosticity perspective. Journal of Consumer Research, 17(4), 454-462.

Hevner, A. R., March, S. T., Park, J., \& Ram, S. (2004). Design Science in information systems research. MIS Quarterly, 28(1), 75-105.

Hinz, O., Schulze, C., \& Takac, C. (2014). New product adoption in social networks: why direction matters. Journal of Business Research, 67(1), 2836-2844.

Hinz, O., Skiera, B., Barrot, C., \& Becker, J. U. (2011). Seeding strategies for viral marketing: an empirical comparison. Journal of Marketing, 75(6), 55-71.

Hogan, J. E., Lemon, K. N., \& Libai, B. (2003). What is the true value of a lost customer? Journal of Service Research, 5(3), 196-208.

Hogan, J. E., Lemon, K. N., \& Libai, B. (2004). Quantifying the ripple: word-of-mouth and advertising effectiveness. Journal of Advertising Research, 44(3), 271-280.

$\mathrm{Hu}$, M., \& Liu, B. (2004, August). Mining and summarizing customer reviews. In Proceedings of the 10th ACM SIGKDD International Conference on Knowledge Discovery and Data Mining (pp. 168177). Seattle.

ITU. (2016). ICT Facts and Figures 2016. http://www.itu.int/en/ITUD/Statistics/Documents/facts/ICTFactsFigures2016.pdf. Accessed $03 \mathrm{Feb} 2017$.

Iyengar, R., Van den Bulte, C., \& Choi, J. (2011a). Distinguishing between drivers of social contagion: insights from combining social network and co-location data. Philadelphia: Working Paper at the Wharton School of the University of Pennsylvania. 
Iyengar, R., Van den Bulte, C., \& Valente, T. W. (2011b). Opinion Leadership and social contagion in new product diffusion. Marketing Science, 30(2), 195-212.

Jain, D., \& Singh, S. S. (2002). Customer lifetime value research in marketing: a review and future directions. Journal of Interactive Marketing, 16(2), 34-46.

Jain, D. C., \& Vilcassim, N. J. (1991). Investigating household purchase timing decisions: a conditional hazard function approach. Marketing Science, 10(1), 1-23.

Kane, G. C., Alavi, M., Labianca, G., \& Borgatti, S. (2014). What's different about social media networks? A framework and research agenda. MIS Quarterly, 38(1), 275-304.

Katona, Z., Zubcsek, P. P., \& Sarvary, M. (2011). Network effects and personal influences: the diffusion of an online social network. Journal of Marketing Research, 48(3), 425-443.

Katz, L. (1953). A new status index derived from sociometric analysis. Psychometrika, 18(1), 39-43.

Katz, E., \& Lazarsfeld, P. F. (1955). Personal influence: the part played by people in the flow of mass Communications. New York: The Free Press.

Katz, M. L., \& Shapiro, C. (1994). Systems competition and network effects. Journal of Economic Perspectives, 8(2), 93-115.

Kiss, C., \& Bichler, M. (2008). Identification of influencers - Measuring influence in customer networks. Decision Support Systems, 46(1), 233-253.

Klier, J., Klier, M., Probst, F., \& Thiel, L. (2014). Customer lifetime network value. In Proceedings of the 35th International Conference on Information Systems (pp. 1-21). Auckland.

Kotler, P., \& Armstrong, G. (1996). Principles of marketing (7th ed.). Englewood Cliffs: Prentice Hall.

Kumar, V., Aksoy, L., Donkers, B., Venkatesan, R., Wiesel, T., \& Tillmanns, S. (2010a). Undervalued or overvalued customers: capturing Total customer engagement value. Journal of Service Research, 13(3), 297-310.

Kumar, V., Bhaskaran, V., Mirchandani, R., \& Shah, M. (2013). Creating a measurable social media marketing strategy: increasing the value and ROI of intangibles and tangibles for hokey pokey. Marketing Science, 32(2), 194-212.

Kumar, V., Petersen, J. A., \& Leone, R. P. (2007). How valuable is word of mouth? Harvard Business Review, 85(10), 139-148.

Kumar, V., Petersen, J. A., \& Leone, R. P. (2010b). Driving profitability by encouraging customer referrals: who, when, and how. Journal of Marketing, 74(5), 1-17.

Kumar, V., Ramani, G., \& Bohling, T. (2004). Customer lifetime value approaches and best practice Applications. Journal of Interactive Marketing, 18(3), 60-72.

Kumar, V., Venkatesan, R., Bohling, T., \& Beckmann, D. (2008). The power of CLV: managing customer lifetime value at IBM. Marketing Science, 27(4), 585-599.

Lee, J., Lee, J., \& Feick, L. (2006). Incorporating word-of-mouth effects in estimating customer lifetime value. Journal of Database Marketing \& Customer Strategy Management, 14(1), 29-39.

Libai, B., Muller, E., \& Peres, R. (2013). Decomposing the value of word-of-mouth seeding programs: accelerations versus expansion. Journal of Marketing Research, 50(2), 161-176.

Lin, F., \& Cohen, W. W. (2010). Power iteration clustering. In Proceedings of the 27th International Conference on Machine Learning (ICML) (pp. 655-662). Haifa.

Lis, B., \& Neßler, C. (2014). Electronic word of mouth. Business \& Information Systems Engineering, 6(1), 63-65.

Liu, X., He, Q., Tian, Y., Lee, W.-C., McPherson, J., \& Han, J. (2012). Event-based social networks: linking the online and offline social worlds. In Proceedings of the 18th ACM SIGKDD International Conference on Knowledge Discovery and Data Mining (pp. 10321040). Beijing.
Malthouse, E. C., \& Blattberg, R. C. (2005). Can we predict customer lifetime value? Journal of Interactive Marketing, 19(1), 2-16.

Malthouse, E. C., Haenlein, M., Skiera, B., Wege, E., \& Zhang, M. (2013). Managing customer relationships in the social media era: introducing the social CRM house. Journal of Interactive Marketing, 27(4), 270-280.

McAlexander, J. H., Schouten, J. W., \& Koenig, H. F. (2002). Building brand community. Journal of Marketing, 66(1), 38-54.

Moon, S., Bergey, P. K., \& Iacobucci, D. (2010). Dynamic effects among movie ratings, movie revenues, and viewer satisfaction. Journal of Marketing, 74(1), 108-121.

Mtibaa, A., May, M., Diot, C., \& Ammar, M. (2010). PeopleRank: social opportunistic forwarding. In Proceedings of the 29th Conference on Information Communications (pp. 1-5). San Diego.

Nahon, K., \& Hemsley, J. (2013). Going Viral. Cambridge: Polity Press.

Nielsen (2015). Word-of-mouth recommendations remain the most credible. http://www.nielsen.com/id/en/press-room/2015/WORD-OFMOUTH-RECOMMENDATIONS-REMAIN-THE-MOSTCREDIBLE.html. Accessed 03 Feb 2017.

Nitzan, I., \& Libai, B. (2011). Social effects on customer retention. Journal of Marketing, 75(6), 24-38.

Oestreicher-Singer, G., Libai, B., Sivan, L., Carmi, E., \& Yassin, O. (2013). The network value of products. Journal of Marketing, 77(3), 1-14.

Page, L., Brin, S., Motwani, R., \& Winograd, T. (1999). The PageRank citation ranking: bringing order to the web. Stanford: Technical Report, Stanford InfoLab.

Pang, B., \& Lee, L. (2008). Opinion mining and sentiment analysis. Foundations and Trends in Information Retrieval, 2(1-2), 1-135.

Peffers, K., Tuunanen, T., Rothenberger, M. A., \& Chatterjee, S. (2007). A design science research methodology for information systems research. Journal of Management Information Systems, 24(3), 4578.

Probst, F., Grosswiele, L., \& Pfleger, R. (2013). Who will lead and who will follow: identifying influential users in online social networks: a critical review and future research directions. Business \& Information Systems Engineering, 5(3), 179-193.

Rossmann, A., Ranjan, K. R., \& Sugathan, P. (2016). Drivers of user engagement in eWoM communication. Journal of Services Marketing, 30(5), 541-553.

Scarpi, D., Pizzi, G., \& Visentin, M. (2014). Shopping for fun or shopping to buy: is it different online and offline? Journal of Retailing and Consumer Services, 21(3), 258-267.

Schmitt, P., Skiera, B., \& Van den Bulte, C. (2011). Referral programs and customer value. Journal of Marketing, 75(1), 46-59.

Singh, S. S., \& Jain, D. C. (2013). Measuring customer lifetime value: models and analysis. INSEAD Working Paper(2013/27/MKT).

Soares, M. A., \& Pinho, C. J. (2014). Advertising in online social networks: the role of perceived enjoyment and social influence. Journal of Research in Interactive Marketing, 8(3), 245-263.

Solomon, M. (2015). The year of the millennial customer: is your customer experience ready? http://www. forbes $\mathrm{com} / \mathrm{sites} / \mathrm{micahsolomon} / 2015 / 11 / 14 / 2016$-is-the-year-of-themillennial-customer-heres-how-to-be-ready/\#25e08a506e72. Accessed 03 Feb 2017.

Tang, C., \& Guo, L. (2015). Digging for gold with a simple tool: validating text mining in studying electronic word-of-mouth (eWOM) communication. Marketing Letters, 26(1), 67-80.

The CMO Survey. (2016). Driving toward the digital marketing organization. https://cmosurvey.org/. Accessed 03 Feb 2017.

Trusov, M., Bodapati, A. V., \& Bucklin, R. E. (2010). Determining influential users in Internet social networks. Journal of Marketing Research, 47(4), 643-658.

Van den Bulte, C., \& Wuyts, S. (2007). Social networks and marketing. Relevant knowledge series. Cambridge: Marketing Science Institute. 
Venkatesan, R., \& Kumar, V. (2004). A customer lifetime value framework for customer selection and resource allocation strategy. Journal of Marketing, 68(4), 106-125.

Verhoef, P. C., \& Lemon, K. N. (2013). Successful customer value management: key lessons and emerging trends. European Management Journal, 3l(1), 1-15.

Villanueva, J., Yoo, S., \& Hanssens, D. M. (2008). The impact of marketinginduced versus word-of-mouth customer acquisition on customer equity growth. Journal of Marketing Research, 45(1), 48-59.

von Stieglitz, S., Dang-Xuan, L., Bruns, A., \& Neuberger, C. (2014). Social media analytics - an interdisciplinary approach and its implications for information systems. Business \& Information Systems Engineering, 6(2), 89-96.

Wang, G., Jiang, W., Wu, J., \& Xiong, Z. (2014). Fine-grained featurebased social influence evaluation in online social networks. IEEE Transactions on Parallel and Distributed Systems, 25(9), 2286-2296.

Wangenheim, F. v., \& Bayón, T. (2007). The chain from customer satisfaction via word-of-mouth referrals to new customer acquisition. Journal of the Academy of Marketing Science, 35(2), 233-249.
Wasserman, S., \& Faust, K. (1994). Social network analysis: Methods and Applications. Structural analysis in the social sciences (Vol. 8). Cambridge: Cambridge University Press.

Watts, D. J., \& Dodds, P. S. (2007). Influentials, networks, and public opinion formation. Journal of Consumer Research, 34(4), 441-458.

Weinberg, B. D., \& Berger, P. D. (2011). Connected customer lifetime value: the impact of social media. Journal of Direct, Data and Digital Marketing Practice, 12(4), 328-344.

Wilson, C., Boe, B., Sala, A., Puttaswamy, K. P., \& Zhao, B. Y. (2009, April). User interactions in social networks and their implications. In Proceedings of the 4th ACM European Conference on Computer Systems (pp. 205-218). Nuremberg.

WOMMA. (2014). The State of WOMM. https://womma.org/the-stateof-womm-2014/. Accessed 03 Feb 2017.

Zhang, Y., Zhou, J., \& Cheng, J. (2011). Preference-based top-K influential nodes Mining in Social Networks. In Proceedings of the 2011 I.E. 10th International Conference on Trust, Security and Privacy in Computing and Communications (pp. 1512-1518). Changsha. 